\title{
Influence of local geoid variation on water surface elevation estimates derived from multi-mission altimetry for Lake Namco
}

\author{
Jiang, Liguang; Andersen, Ole Baltazar; Nielsen, Karina; Zhang, Guoqing; Bauer-Gottwein, Peter
}

Published in:

Remote Sensing of Environment

Link to article, DOI:

10.1016/j.rse.2018.11.004

Publication date:

2019

Document Version

Peer reviewed version

Link back to DTU Orbit

Citation (APA):

Jiang, L., Andersen, O. B., Nielsen, K., Zhang, G., \& Bauer-Gottwein, P. (2019). Influence of local geoid variation on water surface elevation estimates derived from multi-mission altimetry for Lake Namco. Remote Sensing of Environment, 221, 65-79. https://doi.org/10.1016/j.rse.2018.11.004

\section{General rights}

Copyright and moral rights for the publications made accessible in the public portal are retained by the authors and/or other copyright owners and it is a condition of accessing publications that users recognise and abide by the legal requirements associated with these rights.

- Users may download and print one copy of any publication from the public portal for the purpose of private study or research.

- You may not further distribute the material or use it for any profit-making activity or commercial gain

- You may freely distribute the URL identifying the publication in the public portal 


\title{
Influence of local geoid variation on water surface elevation estimates derived from multi-mission altimetry for Lake Namco
}

\author{
Liguang Jiang a,*, Ole Baltazar Andersen ${ }^{\text {b }}$, Karina Nielsen b , Guoqing Zhang c, d, Peter \\ Bauer-Gottwein ${ }^{\text {a }}$ \\ a Department of Environmental Engineering, Technical University of Denmark, 2800 Kgs. \\ Lyngby, Denmark \\ b Division of Geodesy, National Space Institute, Technical University of Denmark, 2800 \\ Kgs. Lyngby, Denmark \\ c Key Laboratory of Tibetan Environment Changes and Land Surface Processes, Institute of \\ Tibetan Plateau Research, Chinese Academy of Sciences, Beijing 100101, China \\ d CAS Center for Excellence in Tibetan Plateau Earth Sciences, Beijing 100101, China \\ * Corresponding author. Email address: 1jia@env.dtu.dk
}


Abstract: Water surface elevation (WSE) is an essential quantity for water resource monitoring and hydrodynamic modeling. Satellite altimetry has provided data for inland waters. The height that is derived from altimetry measurement is ellipsoidal height. In order to convert the ellipsoidal height to orthometric height, which has physical meaning, accurate estimates of the geoid are needed. This paper evaluates the suitability of geodetic altimetric measurements for improvement of global geoid models over a large lake in the Tibetan Plateau. CryoSat-2 and SARAL/AltiKa are used to derive the high-frequency geoid correction. A validation of the local geoid correction is performed with data from in-situ observations, a laser altimetry satellite (ICESat), a Ka-band radar altimetry satellite (SARAL) and a SAR radar altimetry satellite (Sentinel-3). Results indicate that, geodetic altimetric dataset can capture the high-resolution geoid information. By applying local geoid correction, the precision of ICESat, SARAL and Sentinel-3 retrievals are significantly improved. We conclude that using geodetic altimetry to correct for local geoid residual over large lakes significantly decreases the uncertainty of estimates of WSE. These results also indicate the potential of geodetic altimetry missions to determine local geoid residual with centimeterlevel accuracy, which can be incorporated to improve global and regional geopotential models.

Keywords: satellite altimetry; CryoSat-2; water level; local geoid; Lake Namco

\section{Introduction}

Terrestrial freshwater is a crucial resource for all terrestrial life and human activities, although it represents less than 3\% of the total water storage on the planet (Dingman, 2015). With increasing population, freshwater resources are under growing pressure in parts of the world, and managers face difficult trade-offs between human needs for water and ecosystem water requirements. Water surface elevation (WSE) is one of the most important quantities for hydrological research, as it is closely related to water storage and exchange fluxes in lakes, wetlands, reservoirs, and rivers. WSE change and variability (i.e. annual, interannual, and intraseasonal variability) are important indicators for climate change. However, limited 
availability of in-situ monitoring data impedes comprehensive research of inland hydrology and water resources management (e.g. the spatial and temporal dynamics of freshwater storage, flood forecasting, etc.) especially in developing countries (Alsdorf et al., 2007). Technological advances in recent satellite altimeter missions (e.g. Jason-2/-3, CryoSat-2, SARAL/AltiKa, Sentinel-3, etc.), provide alternative options of measuring WSE of inland water bodies. WSE derived from satellite altimetry is becoming increasingly used for inland water monitoring and hydrodynamic modeling in the hydrology community (e.g. Crétaux et al., 2011; Jiang et al., 2017a, 2017b, Schneider et al., 2018a, 2018b, 2017; Schwatke et al., 2015 among others). Compared to short-repeat missions, e.g. Envisat and Jason, geodetic missions, for example, CryoSat-2, have distinct advantages for surface water monitoring because of the drifting ground track pattern. With its roughly $8 \mathrm{~km}$ ground track spacing at the equator, it detects much more water bodies than any other satellite (Jiang et al., 2017c). However, CryoSat-2's 369 days repeat prevents it from capturing the seasonal signal in small lakes (Nielsen et al., 2015).

The principal of satellite radar altimetry is to measure the travel time of a microwave pulse traveling between the altimeter and water surface, which can be converted into a distance (i.e. range $R$ ). The ellipsoidal height is obtained from orbit height above a reference ellipsoid $(h)$ by subtracting the measured range $R$. The altimeter observes within a range window, which is typically between $30 \mathrm{~m}$ and $120 \mathrm{~m}$ depending on the instrument. The closed-loop tracking (autonomous tracking) system will fail to track the correct range if there are abrupt elevation changes in the terrain exceeding this range (Biancamaria et al., 2017; Dehecq et al., 2013). This is because the closed-loop tracker is heavily dependent on previous measurements for current estimates of range and range rate (Chelton et al., 2001). That is to say, water bodies surrounded by or adjacent to steep mountains are prone to be incorrectly measured. Additionally, due to the large footprint, the inhomogeneous ground surface can lead to incorrect measurements. Therefore, inland water altimetry data can suffer from degradation in quality due to the contamination of surroundings and inaccurate corrections (Abulaitijiang et al., 2015). 
However, the location of a reference ellipsoid is arbitrary in the sense that its center does not coincide with the mass center of the Earth, so ellipsoidal heights have no relationship to gravity and do not give an accurate portrayal of how water flows (Meyer et al., 2006). Instead, the dynamic height is an equipotential surface and water will not flow of the same height (Heiskanen and Moritz, 1967). Nevertheless, dynamic heights are not suitable as practical heights because they are not geometric distances and a large correction that accounts for gravity is needed. See detailed explanation in Heiskanen and Moritz (1967) and Meyer et al. (2006). Orthometric height is widely used in engineering and environmental activities due to its physical and geometric meaning and ability to predict fluid flows in many situations (Erol, 2011; Heiskanen and Moritz, 1967; Yilmaz, 2008). Orthometric height is approximated by subtracting geoid height from ellipsoid height. Therefore, an accurate geoid model is needed to convert ellipsoidal heights to orthometric heights.

The idealized of equipotential surface of the oceans was proposed as the "mathematical figure of the Earth" and was later termed the "geoid" (Heiskanen and Moritz, 1967). There have been many definitions of the "geoid" and NGS defines it as "the equipotential surface of the Earth's gravity field which best fits, in the least squares sense, global mean sea level" (National Geodetic Survey, 1986). The geoid height $(N)$, also called geoid undulation, is defined as "the distance, taken along a perpendicular to the ellipsoid of reference, from that ellipsoid to the geoid' (National Geodetic Survey, 1986). This height varies with location from -107 to $86 \mathrm{~m}$, and the uncertainties of the current most accurate global geoid models (GGMs) are about 18.3 $\mathrm{cm}$ for the land areas according to the EGM2008 (Pavlis et al., 2012). Global geoid models such as EGM2008, do not represent high frequency geoid undulations (i.e. within 5 arc mins or $\sim 9 \mathrm{~km}$ ). This problem is known as the omission error in gravity field modeling (Hirt et al., 2010). However, the Earth's geoid has significant structure at smaller scales (Mazloff et al., 2014). Several studies have indicated that this problem is more severe over rugged mountainous areas, like the Himalaya and the Andes due to the too sparse terrestrial gravity data used in GGMs (Li et al., 2015; Pavlis et al., 2012; She et al., 2016). Fig. 1 shows the height difference 
between two widely used geoid models over the Lake Namco on Tibetan Plateau. The difference is in the range of -0.05 to $0.35 \mathrm{~m}$ with significant structure, which can result in errors if e.g., altimetry is averaged along track to derive mean height of the lake. Therefore, an imprecise geoid model can affect the estimated WSE (especially for long-repeat missions) and hydrodynamic simulations.
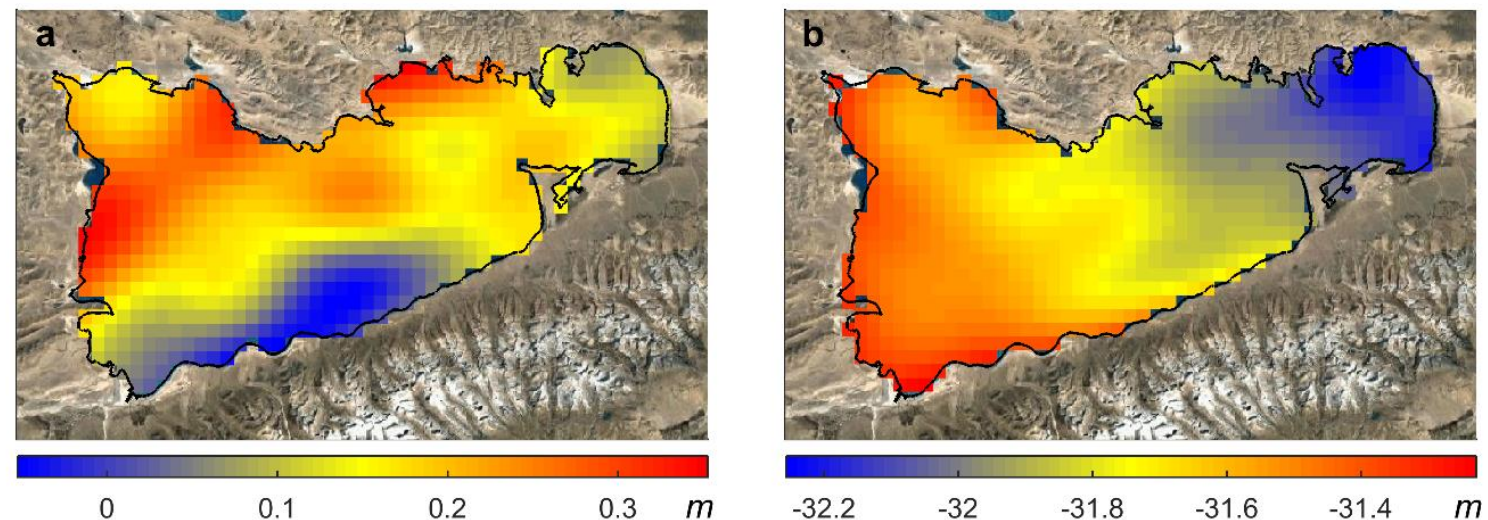

Fig. 1. Illustration of (a) geoid height difference between EGM2008 (Pavlis et al., 2012) and GOCO05c (Fecher et al., 2017) and (b) EGM2008 height over the Lake Namco in Tibetan Plateau

Over the past decade, many studies have investigated changes in WSE of lakes over the Himalaya regions (Hwang et al., 2016; Jiang et al., 2017a; Song et al., 2014; Tseng et al., 2016; Zhang et al., 2011) with the increasing availability of altimetry data sets. However, time series for lakes in these mountainous regions need to be carefully processed. The reason is twofold as aforementioned: first, inaccurate measurements may be included if the complete open water mask is used to select the altimetry data; second, local geoid variations can induce large uncertainty because those variations can reach amplitudes of $15 \mathrm{~cm}$ or even larger in mountainous areas for GGMs (Hirt, 2011). This error would probably be propagated into model simulation when hydrodynamic numerical models are used for nutrient management, biogeochemical processes simulation, hydraulic structures, etc. (Seo et al., 2010; Xue et al., 2017; Zandagba et al., 2016). This issue is especially important for geodetic missions, like CryoSat-2 and SARAL, due to geoid height variation along and across ground tracks. 
Kleinherenbrink et al. (2014) briefly mentioned that the inaccuracy in geoid model can induce water surface slope. Crétaux et al. (Crétaux et al., 2011) also emphasized that it is necessary to correct for the slope of the geoid because geoid models do not correctly map high-frequency variations over large lakes.

The aim of this paper is to exploit satellite radar altimetry data in improving local geoid estimates over inland waters. To this end, we collect altimetry data from different missions, i.e., CryoSat-2, SARAL, Sentinel-3 and ICESat. Here, we derive a local geoid correction field using geodetic measurements from CryoSat-2 and SARAL (drifting phase). Furthermore, we use high-resolution ICESat data to validate the improved geoid model (EGM2008). Finally, we extend the validation to SARAL and Sentinel-3 to demonstrate the effect of geoid variations on WSE estimates.

\section{Materials and Methods}

\subsection{Study site}

Lake Namco is the second largest lake on the Tibetan Plateau with an area of about 2024 $\mathrm{km}^{2}$ and a maximum depth of over $90 \mathrm{~m}$ (Wang et al., 2009). It is an endorheic lake bounded by the Nyainqentanglha Mountains in the south, and several small mountains in the north (Fig. 2). It is replenished by precipitation and glacier melting runoff. The tributaries are mainly coming from the west and the south. Namco is located on the northeast flank of Nyainqentanglha Mountains. The lake generally stretches from west to east with a length of over $70 \mathrm{~km}$ and is well sampled by CryoSat-2. The lake level has risen rapidly over the last two decades (Lei et al., 2013), and it is still rising (Jiang et al., 2017a). This lake is chosen for two reasons; it is large enough, which allows us to solve short-wavelength variation and it is close to high mountains where the geoid models are affected by topographic effect (Akyilmaz et al., 2009; Forsberg, 1985). 


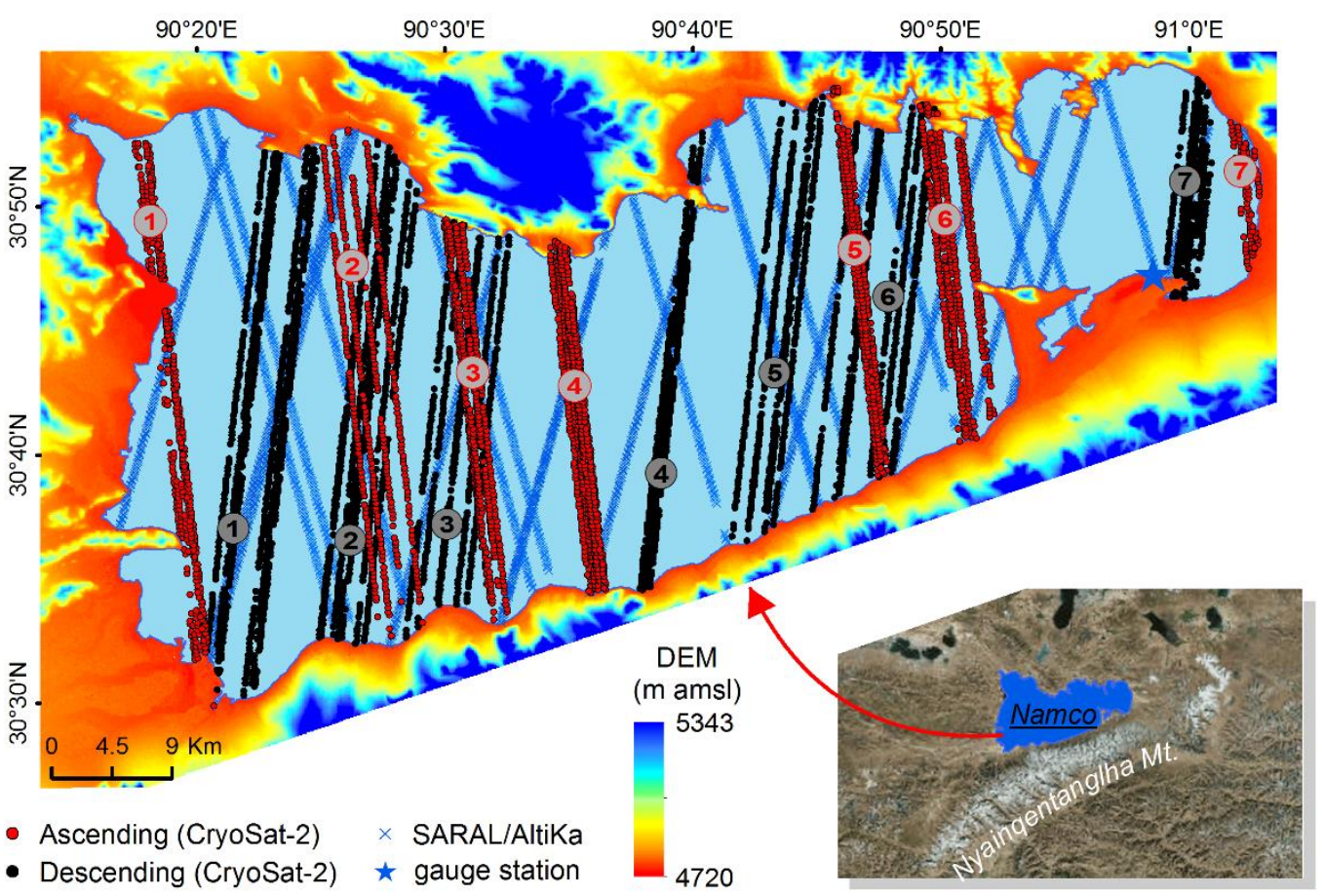

Fig. 2. Map of the study area. The background is ALOS digital surface model with CryoSat-

2 and SARAL/AltiKa altimetric measurements overlaid. Numbers indicate the groups containing several ascending/descending ground tracks of CryoSat-2.

\subsection{CryoSat-2 $20 \mathrm{~Hz}$ SARIn waveforms and data handling}

CryoSat-2 is the first altimetry mission carrying a spaceborne Synthetic Aperture Interferometric Radar Altimeter (SIRAL), which is a state-of-the-art altimeter working in three modes, i.e. low resolution mode (LRM), synthetic aperture mode (SAR), and synthetic aperture interferometric mode (SARIn). SAR mode provides data with a finer along-track spatial resolution (ca. 300m). In SARIn mode two antennas are combined to determine the cross-track angle of arrival of the radar echoes. SARIn mode is activated over the ice-sheet margins, mountain areas, and some other regions, such as Danube River, Congo River, etc. (European Space Agency and Mullar Space Science Laboratory, 2012; Jiang et al., 2017c).

The data used in this study is the baseline $\mathrm{C}$ level $1 \mathrm{~b}$ (L1b) dataset provided by ESA. L1b data files contain geolocated and time stamped waveforms with accompanying altitude, position, corrections, interferometric phase difference, coherence waveforms, etc. Please refer 
to CryoSat-2 Product Handbook (European Space Agency and Mullar Space Science Laboratory, 2012) for a detailed description.

The CryoSat-2 L1b data were retracked with a narrow primary peak threshold (NPPT) retracker (Jain et al., 2015). The chosen threshold depends on the underlying surface, with lower thresholds for ocean and ice sheets, and higher thresholds for inland waters. In this study, we used $80 \%$ to determine the retracking point (Villadsen et al., 2016). We alternatively examined the default ESA retracker and a Gaussian threshold retracker, but NPPT with a threshold of $80 \%$ was most stable. Moreover, SARIn mode data allows us to locate the cross-track location of scatterers (Abulaitijiang et al., 2015). In this study, we only used measurements from nadir.

\subsection{SARAL/AltiKa data}

SARAL/AltiKa is the first altimeter measuring in Ka-band frequency. Measurements in the Ka-band have a reduced footprint (4-5 $\mathrm{km}$ in radius) which results in higher spatial resolution. Another improvement of AltiKa is its enhanced bandwidth $(500 \mathrm{MHz})$, which leads to higher vertical resolution and higher pulse repetition frequency (CNES, 2016). Therefore, it is expected to increase precision and data availability (along-track sampling at $40 \mathrm{~Hz}$ ) and thereby increase sensitivity to the geoid anomaly over inland water located in sloping terrain (Steunou et al., 2015). The SARAL satellite flew on the same repeat orbit as ENVISAT with a 35-day repeat cycle until July 2016, and was then switched to drifting orbit mode.

Geophysical Data Records (GDRs) during 2013 and 2016 were downloaded from CNES AVISO+ program (Centre National D'Etudes Spatiales, Archiving, Validation and Interpretation of Satellite Oceanographic data, ftp://avisoftp.cnes.fr/AVISO/pub/). During the repetitive orbit phase, there are two orbits passing across Lake Namco, i.e. ascending track number 165 and descending track number 524 . For some cycles, the ground track deviates $\sim 10$ $\mathrm{km}$ (depending on the altitude) away from its nominal position. In addition, some cycles have fewer measurements, which do not cover a long distance. In this study, these cycles were not 
used. Moreover, we also use data measured during the drifting phase, i.e. cycle number from 100, for retrieval of local geoid undulation.

\subsection{ICESat/GLAS data}

The Geoscience Laser Altimeter System (GLAS) on ICESat satellite uses a laser system to measure the range, which uses short pulses (6 ns) of infrared light (1064 nm) and visible light $(532 \mathrm{~nm}$ ). The resolution is $\sim 70 \mathrm{~m}$ (footprint diameter) and the spatial sampling alongtrack is $170 \mathrm{~m}$. The precision of ICESat measurements of flat surfaces is $2 \mathrm{~cm}$ within footprint size (Zwally et al., 2008). This can help to measure WSE close to the lakeshore and to detect the supposed local geoid residual. ICESat operated during 2003 to 2010. Unfortunately, ICESat suffered from a problem with the onboard lasers, which means that it could only produce data 2-3 times per year. In total, 43 overflights of ICESat/GLA14 altimetry data are available over Lake Namco.

\subsection{Sentinel-3/SRAL data}

A dual-frequency SAR radar altimeter (SRAL) on Sentinel-3 satellite, has some new features. It covers the Earth entirely in the SAR mode, which is designed to achieve finer alongtrack resolution. This property facilitates water surface height measurement close to the coastal areas. Another important characteristic is the tracking mode, i.e. open-loop tracking mode where the altimeter range window is well positioned based on a priori on-board DEM. Therefore, tracking over surfaces with sudden elevation changes is more robust. A detailed introduction can be found in Sentinel-3 User Handbook.

\subsection{WSE from altimetry}

Ranges of all altimetric datasets were first corrected using the associated parameters, i.e. ionosphere correction, dry and wet troposphere corrections, polar tide correction, solid earth tide, retracker correction, geoid height (Jain et al., 2015; Nielsen et al., 2015). Then WSE was calculated using following equation: 


$$
R_{c}=R-R_{r t r k}-R_{g e o}
$$

Here, $h$ is satellite altitude above the reference ellipsoid, $R$ is onboard tracker range, $R_{\text {trtk }}$ is retracking correction, $\mathrm{R}_{\mathrm{geo}}$ is the sum of geophysical corrections, and $\mathrm{N}$ is geoid height referenced to EGM2008.

\subsection{Outlier removal}

To filter outliers in each track, we excluded those beyond two deviations on either side of the median value. As the measurement distribution contain outliers, standard deviation would not yield a representative value. Therefore, a well-known robust estimator of deviation was used, i.e., the median of absolute deviation (MAD). Different from the method of mean plus or minus three standard deviations, which is based on a Gaussian distribution, the MAD is more robust is case of the distribution of water levels is non-Gaussian (Blewitt et al., 2016; Leys et al., 2013). Following steps explain the estimate of deviation.

Step 1: calculate the median of all measurements: $M=$ median (WSE)

Step 2: calculate the absolute deviations from median: $\mathrm{AD}=$ abs (WSE - M)

Step 3: calculate the median of absolute deviations: $M A D=$ median $(A D)$

Step 4: calculate the deviation: $\sigma=1.4826$ MAD

Therefore, measurements within the range of $[M-2 \sigma, M+2 \sigma]$ were used. This procedure was applied to all altimetry data sets.

\subsection{Local geoid correction computing}

Given that the lake surface in hydrostatic equilibrium theoretically represents a gravity potential isosurface (Zlinszky et al., 2014), i.e. dynamic height of the lake is equal everywhere over the lake (Heiskanen and Moritz, 1967), we assume that this equipotential surface mimics the geoid. Considering that the variation of acceleration of gravity is much smaller than geoid uncertainty at the spatial scale we are investigating, we assume the difference of along-track anomalies between dynamic height and orthometric height is negligible (Heiskanen and Moritz, 
1967). Put it differently, we assume that the orthometric height of the lake surface as nearly constant. WSE anomaly of each track was obtained by subtracting the along-track mean value. Therefore the WSE anomaly is mainly subject to geoid residual (Pavlis et al., 2012), which is the short-wavelength variation not solved in global geoid models. By applying Eq. (3) for individual track, anomaly, i.e. $H_{a}$ over the lake is obtained. Further, a local geoid correction filed can be determined by interpolation, and then spatially filtering of $H_{a}$.

$$
H_{a}=W S E-\text { mean }(W S E)
$$

\section{Results}

\subsection{Estimated water levels}

As we can see from Fig. 3, the measurements close to the lakeshore are severely corrupted when CryoSat-2 flies from south to north (ascending orbit). In most cases, the first 15 - 20 measurements are overestimated, which leads to an upward slope instead of a horizontal line in the height profile. Taking group 5 (see Fig. 2) as an example, in this case, even $6 \mathrm{~km}$ away from lakeshore, the WSE is still overestimated (Fig. 3). However, when the ground track is approaching to the lakeshore (from water to land), the observation is barely affected although the mountain is very close (Figs. 2 and 3). Similarly, when CryoSat-2 flies in descending orbit (from north to south), the northern part of the lake is overestimated while the south part is correctly measured (Fig. 4). It should be noted that this effect only occurs when the ground track goes from land to water and the elevation change is steep (larger than the tracking window). This is different from the effect of land contamination, which occurs when the footprint partially illuminates land areas and does not depend on the flight direction. We will address the nature of these noisy water levels in the discussion.

Because the weaker geoid residual may be hidden in the noisy water levels, they are excluded in the further analysis. More specifically, for CryoSat-2 ascending tracks, the measurements within $6 \mathrm{~km}$ from southern lakeshore were discarded. Similarly, for descending 
tracks, those within $6 \mathrm{~km}$ from northern lakeshore were excluded. Thus, the remaining measurements still cover the lakeshore areas. Six km is based on visual examination. Moreover, we also excluded the measurements during ice-bound period, i.e. $1^{\text {st }}$ January to $31^{\text {st }}$ May (Ke et al., 2013; Kropáček et al., 2013).

In order to better sample the whole lake, we also used data from SARAL during the drifting phase (hereafter as SARAL-DF). SARAL-DF also have noisy water level elevations over the lakeshore areas, therefore we excluded those within $2 \mathrm{~km}$ from shoreline. Similarly, measurements during cold season were removed. See the distribution of measurements in Fig. 1.
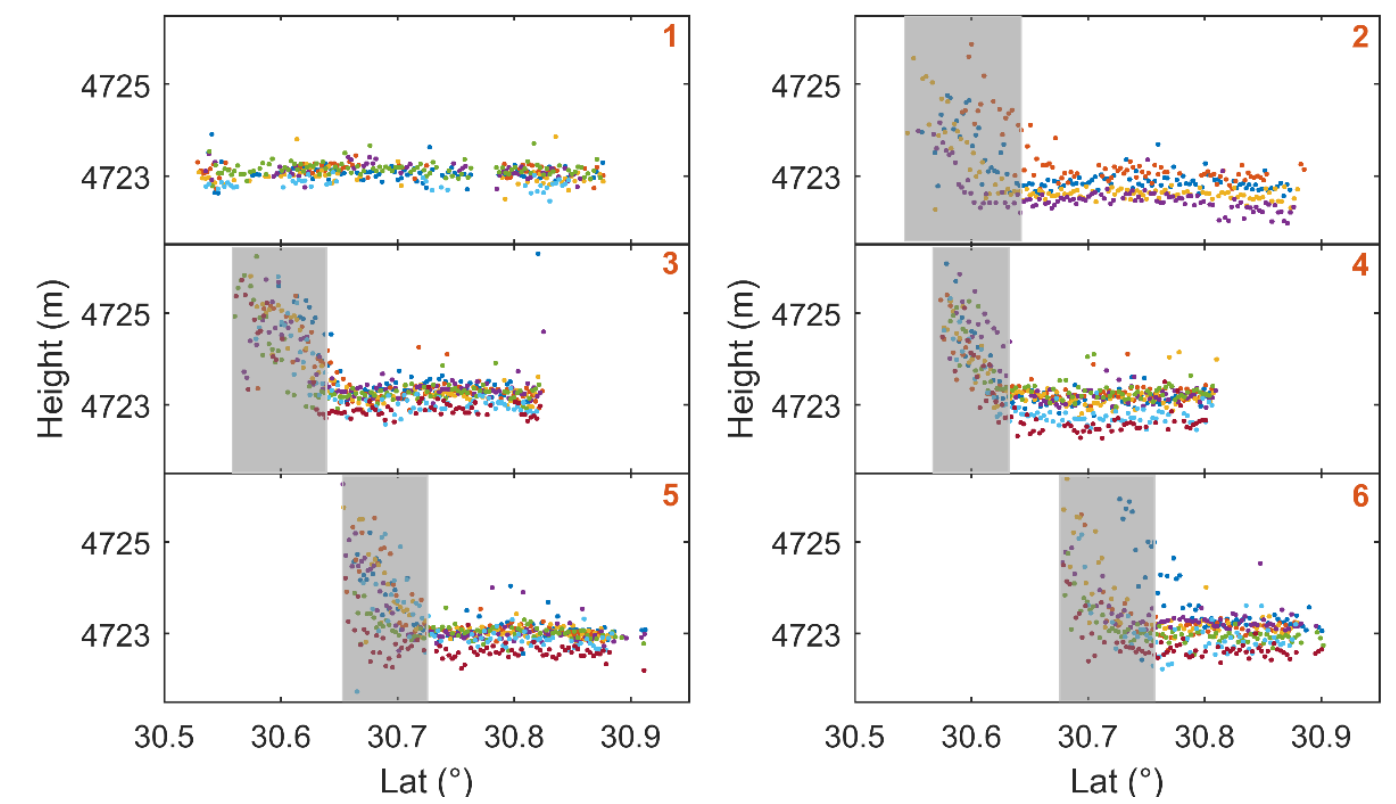

Fig. 3. Along-track measurement profiles of ascending tracks from Cryosat-2, i.e. satellite flies from low latitude to high latitude. Color corresponds to individual track. Number of each plot please refer to group number in Fig. 2. Grey box highlights the incorrect measurements. 

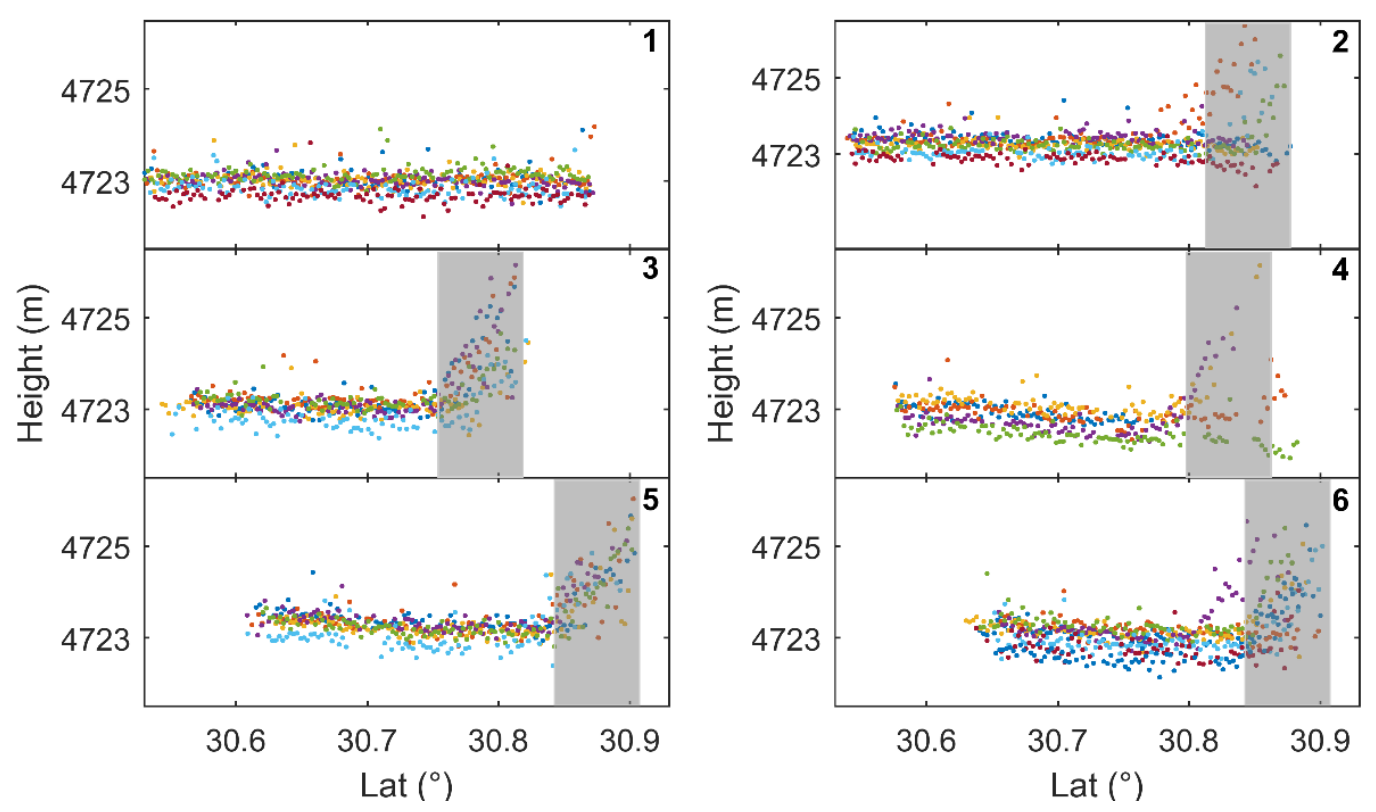

Fig. 4. Along-track measurement profiles of descending tracks from Cryosat-2, i.e. satellite flies from high latitude to low latitude. Color corresponds to individual track. Number of each plot please refer to group number in Fig. 2. Grey box highlights the incorrect measurements.

\subsection{Small-scale geoid signal and geoid variation}

Fig. 5 displays local geoid correction field and corresponding corrected EGM2008 geoid model over Lake Namco. The correction is of a few decimeters and shows significant smallscale structure. Large corrections are along the south lakeshore, where it is in the magnitude of $15 \mathrm{~cm}$. As expected, the geoid is underestimated (positive correction) close to the Nyainqentanglha Mountains (i.e. the red-coded pixels in Fig. 5a) because the mountain mass outside the geoid is not correctly solved in spherical harmonic models. Therefore, it can be argued that the impact of the high-frequency terrain effect on geoid is noticeable. It is likely that correction in the northeast corner is a bit overestimated due to less altimetric measurements are used. Nevertheless, the magnitude of local geoid correction is close to the claim that the RMS of EGM2008 commission error for land is $\pm 18.3 \mathrm{~cm}$ (Pavlis et al., 2012). We created a finer geoid model by adding this local geoid correction to EGM2008 (Fig. 5b). It is obvious that the new geoid mode exhibits a gentle southwestward slope (1/70 000). 

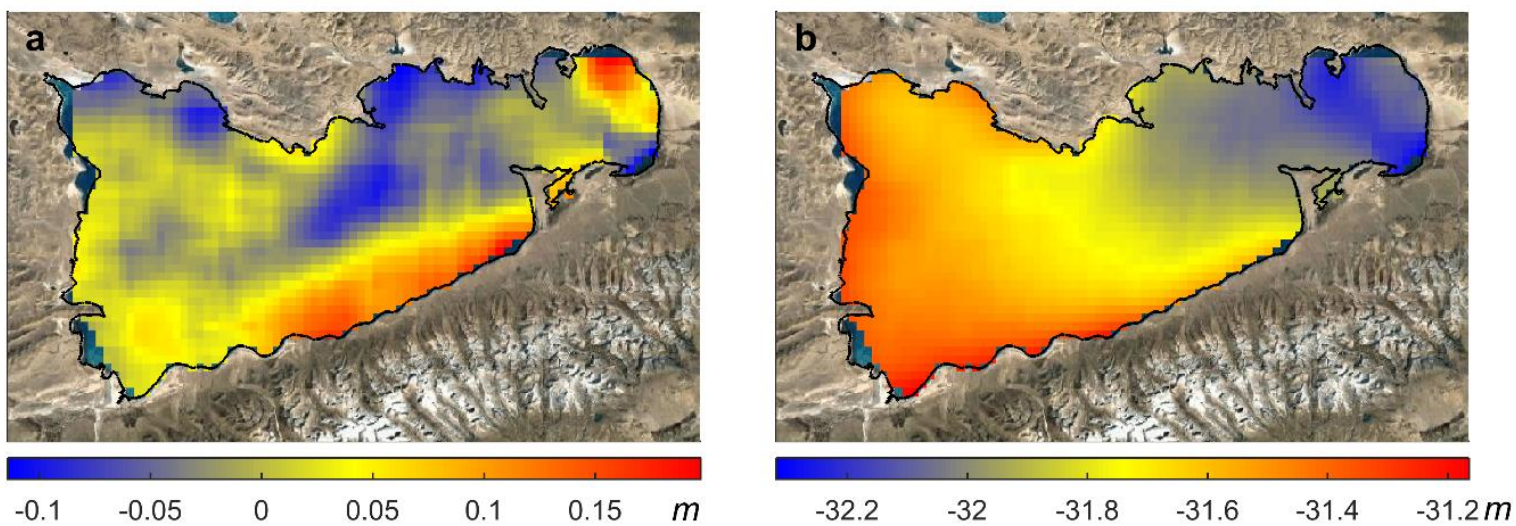

Fig. 5. (a) Map of interpolated local geoid correction derived from CryoSat-2 and SARAL-

DF. Cubic interpolation was used to create this map. (b) Map of corrected EGM2008 geoid model with local geoid correction added.

As shown in Fig. 6, WSE derived from CryoSat-2 generally agrees well with gauge data. On the other hand, accounting for local geoid residual indeed helps to improve WSE precision and accuracy by $8 \%$ and $2 \%$, respectively.

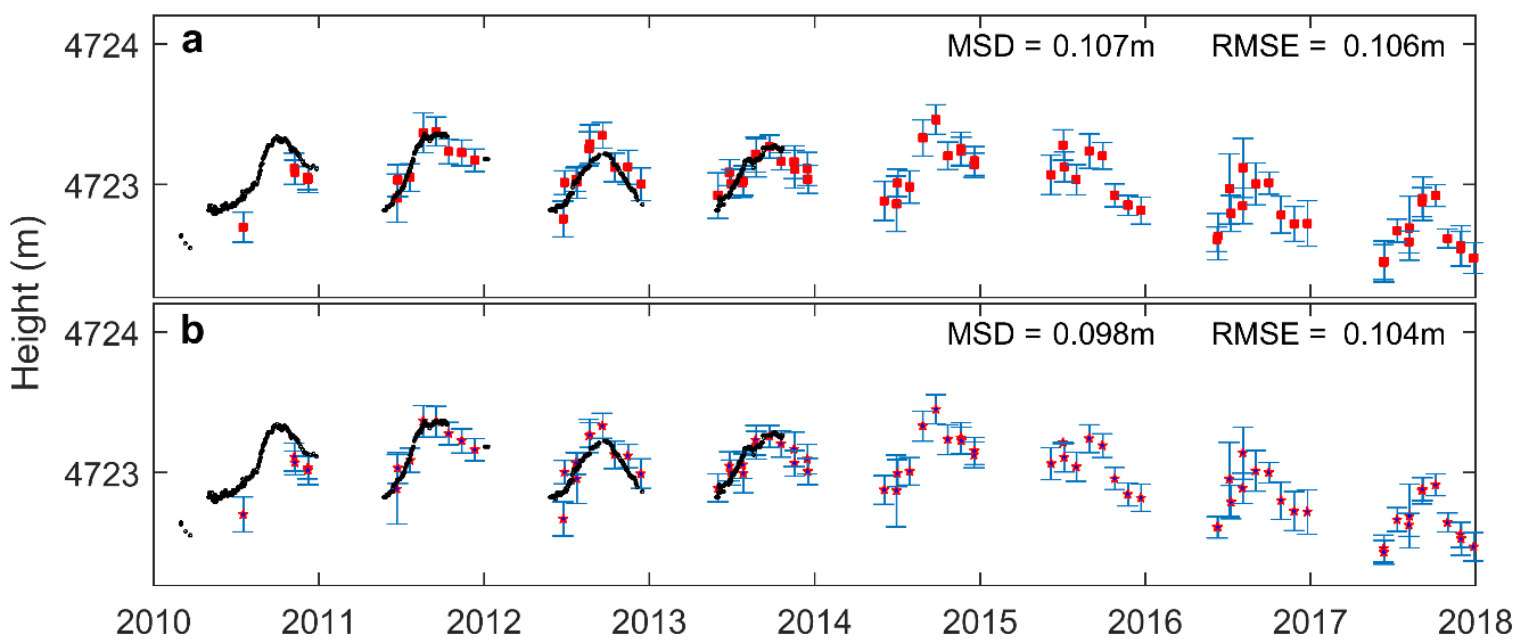

Fig. 6. Time series of WSE derived from CryoSat-2 against in-situ measurements. Black square is in-situ measurement with vertical bias added. Bar indicates standard deviation. (a) WSE is referenced to EGM2008 and (b) WSE is referenced to corrected EGM2008.

\subsection{Validation}


In this section, we validate the local geoid correction field by comparing the standard deviation of measurements per track before and after applying this correction. Median of the standard deviation (MSD) is used to evaluate the performance for three data sets. As stated in Section 2, we only use measurements during ice-free period.

\subsubsection{ICESat}

There are 21 out of 43 tracks crossing Lake Namco. As shown in Fig. 7, these tracks mainly transect four locations and thus we categorized them into 4 groups. Groups 1-3 show clear curving shapes in the height profiles. The geoid close to the south lakeshore is underestimated due to the mountain ranges (see Fig. 2). After applying the local geoid correction, ICESat height profiles are almost horizontal, especially for the first 3 groups which have long cross-over distance $(>20 \mathrm{~km})$.

Data precision before and after applying the local geoid correction was evaluated in terms of MSD. MSDs of most tracks (14/21) are reduced and the MSD of all tracks decreases from $0.070 \mathrm{~m}$ to $0.064 \mathrm{~m}$. For the second and third groups, the improvement of precision is striking, i.e. by $58 \%$ and $30 \%$ on average, respectively. For group 3 (only one track), the correction has a positive effect although the statistics is not very high due to several peaky measurements (Fig. 7). In contrast, group 4 does not improve much. This is probably because the small-scale geoid variations in the eastern part of Namco is less significant (Fig. 5). 

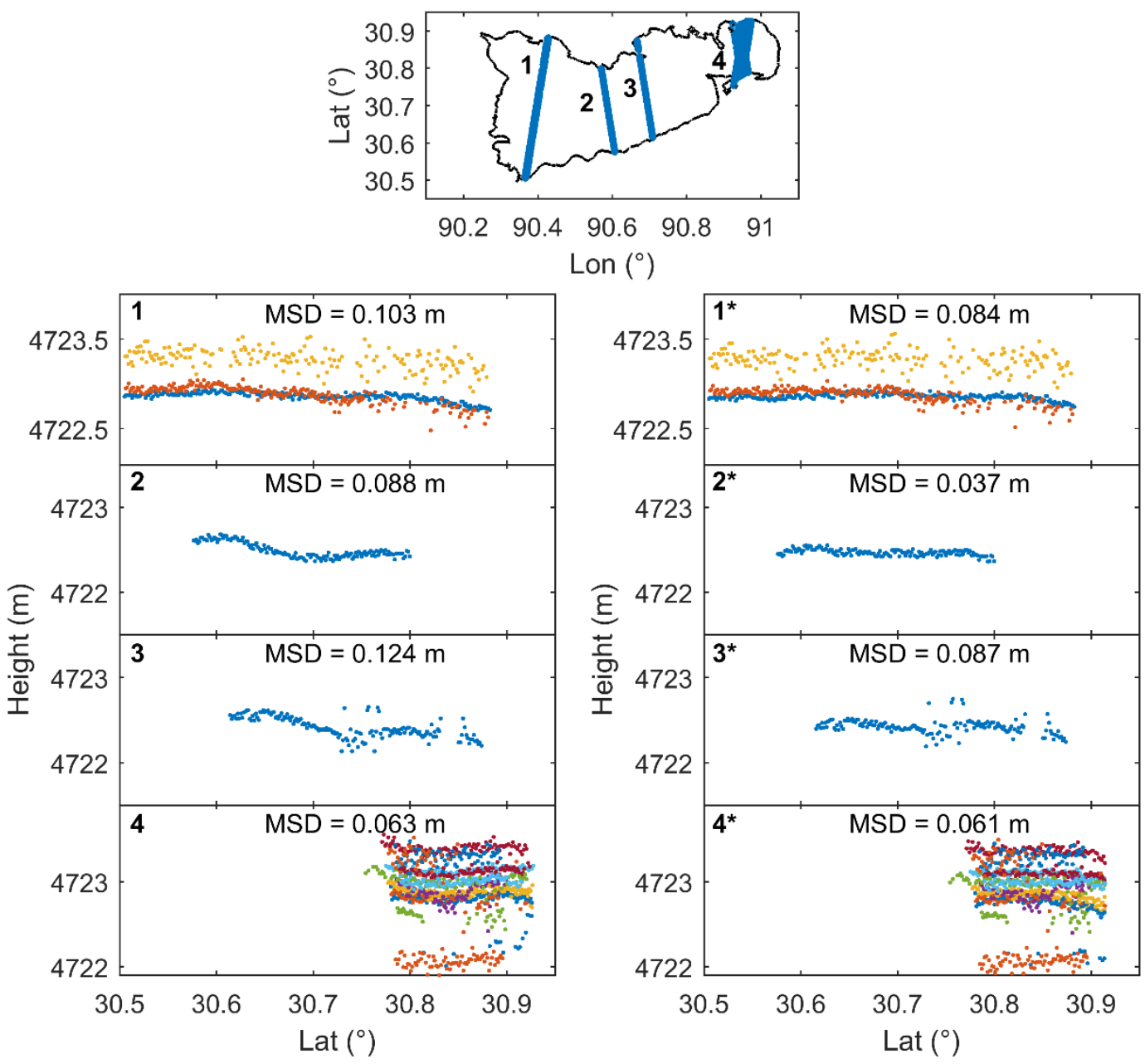

Fig. 7. Along-track measurement profiles from ICESat. Numbers in the bottom four rows are shown in top figure (* indicates corrected one). The data are referenced to EGM2008 (left column) and our enhanced EGM2008 (right column). By referencing to the improved geoid, the profiles become better levelled. See the median standard deviation (MSD) in each plot.

\subsubsection{SARAL}

Similar to ICESat, SARAL also presents curving shapes in water height profiles (Fig. 8).

Group 1 shows the same curve shape as group 2 of ICESat, i.e., the WSE increases from the lowest point at around $30.71^{\circ}$ to both sides. Again, curving is effectively removed by correction for local geoid residuals. Here group 2 exhibits a significant slope, which obviously cannot be left out. Similarly, height profiles are almost level when considering local geoid correction. As shown in Fig. 8, MSD is significantly improved. It is worthwhile to mention that the MSD of 
Note that, for most cycles, missing measurements are mainly the first few kms to the lakeshore, especially for group 1 (Fig. 8). This is also seen in other cycles in drifting phase (Fig. 2). This is mainly related to altimeter tracking performance over sloping terrain, especially over regions with high relief as stated in Quality Assessment Report (ftp://avisoftp.cnes.fr/AVISO/pub/saral/).
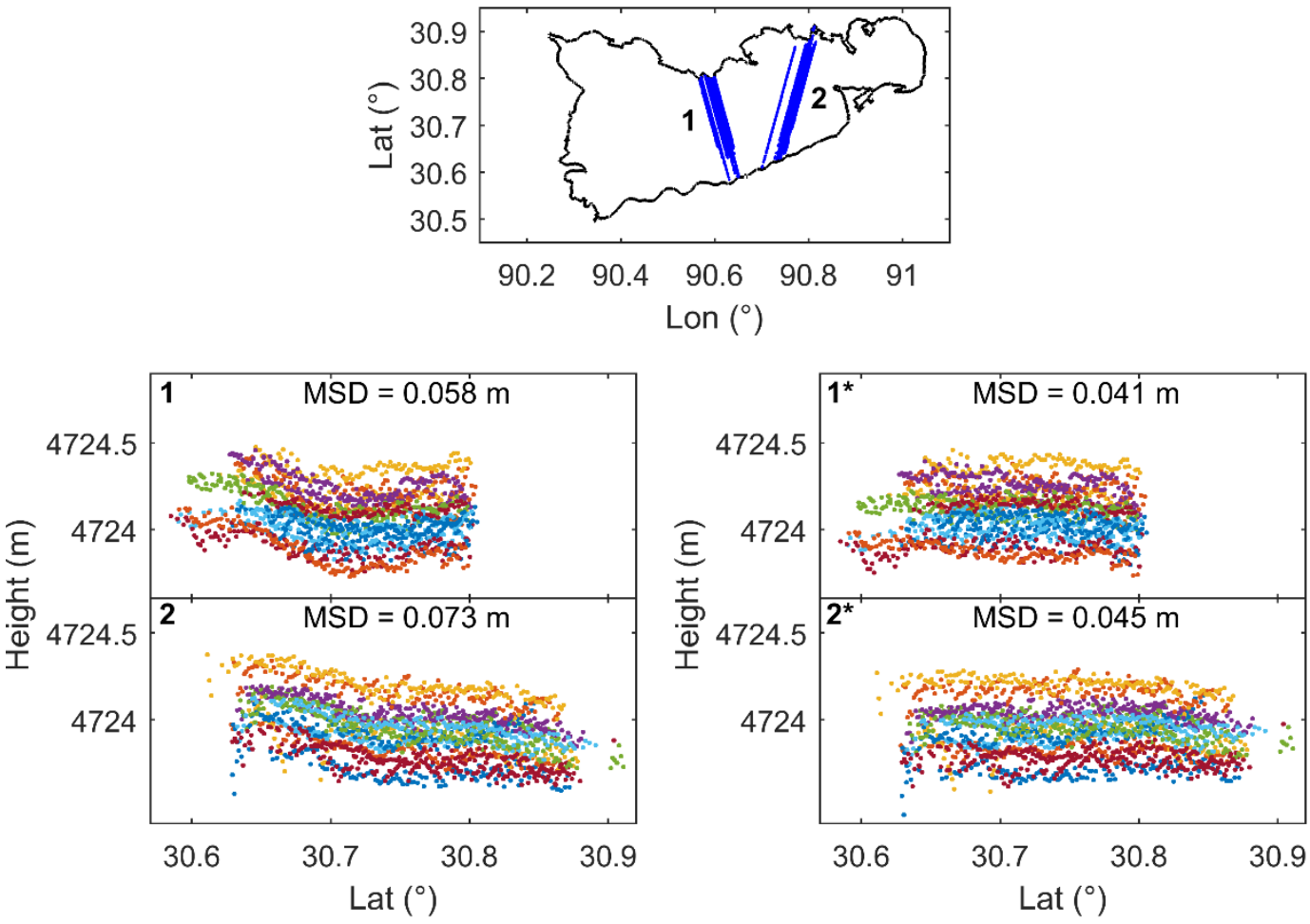

Fig. 8. Along-track measurement profiles of repeat tracks from SARAL. Numbers in the bottom four rows are shown in top figure (* indicates corrected one). Data are referenced to EGM2008 (left column) and enhanced EGM2008 (right column). Median standard deviation (MSD) is given in each plot.

\subsubsection{Sentinel-3}

As shown in Fig. 9, a trough appears in the middle of the tracks, i.e. around $30.7^{\circ} \mathrm{N}$, showing a very similar pattern as exhibited in group 1 of SARAL. As we can see, it is improved in visual and statistical manners after geoid correction applied $(9 \mathrm{~cm}$ vs $7.7 \mathrm{~cm})$. Compared with ICESat and SARAL, MSD of Sentinel-3 is slightly larger. However, we can also see that 
Sentinel-3 does not have noisy water levels, and measurements are much better than those of CryoSat-2 and SARAL in coast regions (Fig. 9).
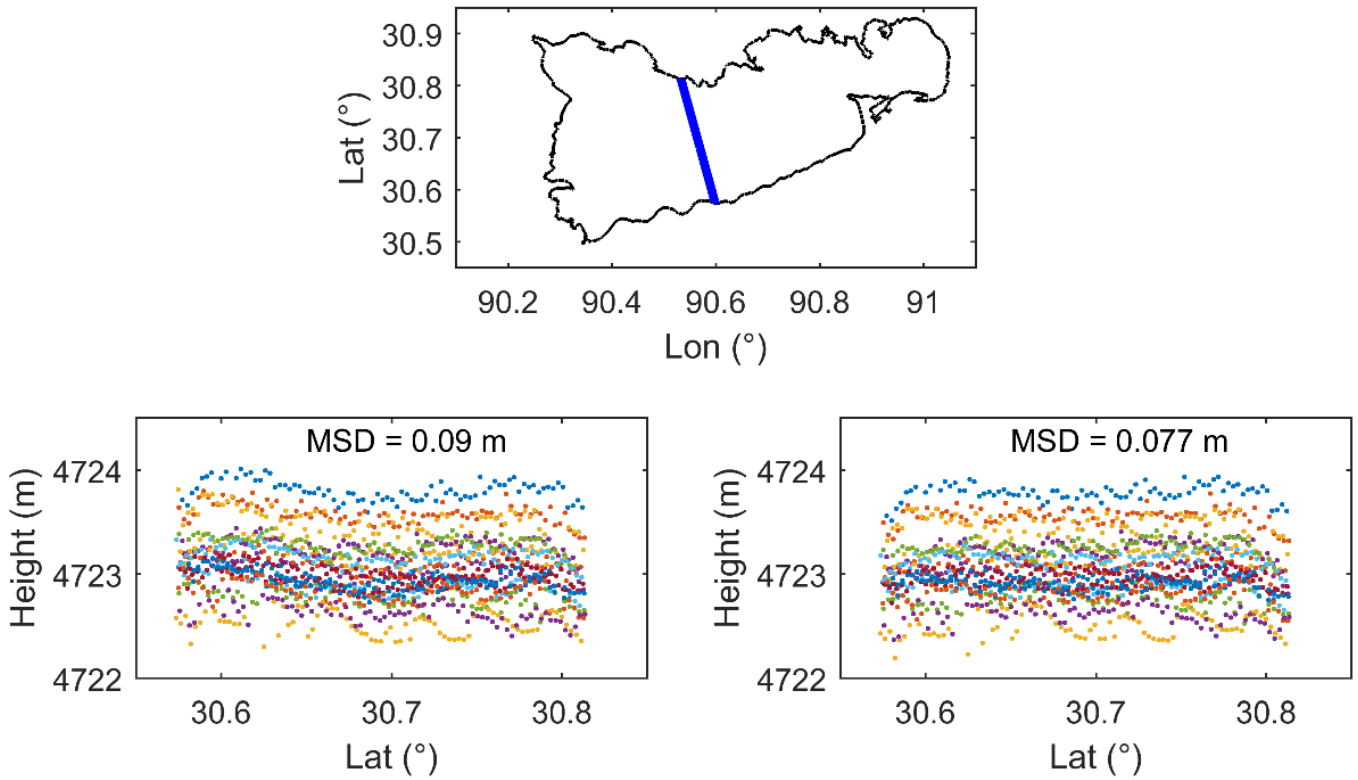

Fig. 9. Along-track measurement profiles of tracks from Sentinel-3. Data are referenced to EGM2008 (left column) and enhanced EGM2008 (right column). Median standard deviation (MSD) is given in each plot.

\section{Discussion}

The reflected signal suffers from land contamination near the water-land transition zone. In general, the degree of contamination is related to orientation and size of the altimeter footprint. In this sense, the signal from SARAL is prone to be contaminated by bright off-nadir features due to its large footprint ( $8 \mathrm{~km}$ in diameter). While, for CryoSat-2, it is less likely that the signal is affected at a few kms from lakeshore due to its smaller footprint ( $~ 300 \mathrm{~m}$ or 380 $\mathrm{m}$ if the Hamming window is applied, along-track and $15 \mathrm{~km}$ across-track). Previous studies also demonstrated the high performance of SAR/SARIn altimetry over inland water (Nielsen et al., 2017; Villadsen et al., 2016). However, in this study, the nearshore lake level estimates are too high and the precision (i.e. MSD) is worse than that of SARAL although the latter has a footprint of $8 \mathrm{~km}$ (in diameter). 
As shown in previous sections, Sentinel-3 has the same footprint as CryoSat-2, but it is not influenced by topography. To understand this difference between the water levels obtained from CryoSat-2 and Sentinel-3 we investigated both the multi-looked waveform and the stack (the individual waveforms from all looks) from both missions. We find that the performance of CryoSat-2 is closely related to topography. The CryoSat-2 waveforms are noisy when the satellite is flying over mountains towards the lake (see Figs A1 and A2 in Appendix A). However, the waveforms close to lakeshore are still good when the satellite is approaching the mountains (see Fig. A3 in Appendix A). This is not observed in the Sentinel-3 waveforms (see Figs. B1-B3 in Appendix B). The reason for the noisy CryoSat-2 waveforms is found in the stack (see Fig. C2 in Appendix C). In the nearshore measurements only a few looks capture the water surface. This is most likely because the tracking window is still adjusted to the higher topography for most of the bursts that is used to form the multi-looked waveform. When only a few looks are available the multi-looked waveform will as a consequence be noisier. As the satellite gets further away from the shore, more looks capture the water surface resulting in a gradually smoother waveform (see Figs A1, A2, and C2 in Appendix A and C). On the contrary, when satellite moves away from the lake, even a few kms away from lake, the backwardlooking looks can still detect water, because the tracking window is still positioned referencing to the lake elevation instead of the higher mountain elevation. Moreover, As shown in Appendix C, CryoSat-2 multi-looks from different bursts are probably misaligned in range, which leads to unwanted smearing of multi-looked waveform after the multi-looking processing (Dinardo and Benveniste, 2013). This is different from Sentinel-3 looks, where a part of the looks are removed leading to a 'clean' multi-looked stack (Appendix C). Hence, we anticipate that the noisy water levels shown in Figs. 3 and 4 are due to errors in the retracking because of the noisy waveforms. It is unlikely that waveforms are polluted by land because the measurements at the moment the satellite moves away from the lake have the same condition (i.e. footprint covers both water and land) as those measured when the satellite moves towards the lake from land. This can also be justified by CryoSat-2 and Sentinel-3 waveforms (see waveforms in Appendix 
A and B). Therefore, this problem is very likely attributed to CryoSat-2 processor and a slowly adjusting tracker. It is beyond the focus of this study. However, even though we do not know the exact problem with CryoSat-2 altimeter instrument, it does have problems over rugged high relief mountainous regions. In this regard, Sentinel-3 data outperforms the CryoSat-2 data.

Laser altimetry (e.g. ICESat) seamlessly measures across land-water transitions due to the smaller laser footprint (Zwally et al., 2002). Radar altimeters, which operate in low resolution mode, suffers from the off-nadir ranging due to large footprint, and limitations in the ability to determine a precise geolocated elevation (Brenner et al., 2007). The error contributions ('budget') to water WSE measurements derived from satellite altimetry, mainly arise from the instrument system, such as orbit determination error, range error, angle determination error, etc., and other atmospheric and geophysical corrections (Wingham et al., 2006; Zwally et al., 2002). Considering that the range error dominates the root-sum-square (RSS) of the error budget (on the order of $10 \mathrm{~cm}$ ), smaller footprint and high pulse repetition frequency could be helpful to mitigate the range error, which has already shown by Sentinel-3 and SARAL (Bonnefond et al., 2018).

On the other hand, geoid model error (on the order of $\pm 18 \mathrm{~cm}$ of EGM2008) will affect orthometric height, which is most commonly used in hydrology. The influence of geoid variations on inland water height estimates is not well studied and understood. It should be kept in mind that this can be important source of error in WSE time series construction from drifting ground-track datasets and hydrodynamic modelling, especially in mountainous areas because current global geoid models have larger uncertainty at local scale. In our study, the results show that local geoid variations omitted in global geoid models contributes significantly to the uncertainty of altimetry-based estimates of WSE. This will have an impact on monitoring of lake surface changes, especially for those having changes in the order of magnitude of a few centimeters. Even in the lowland area, the local geoid height induces uncertainty to WSE.

Naturally, we can derive the mean lake level for a track even if the surface is sloping (inaccurate geoid) and we use sophisticated methods to account for this and to improve 
estimates. However, with an accurate geoid model the derivation of the mean is more robust and not so sensitive to i.e., use of various tracks in the lake and editing of point along the track. This makes the estimation of hydrological parameters like the time variation of the lake level more robust. Furthermore, for hydrodynamic modelling, each individual observation is important to model simulation. Geoid errors of decimeter could affect surface slope, which in turn will result in different water levels.

Thanks to the geodetic CryoSat-2 and SARAL missions, we are able to retrieve a local geoid correction, which can be used to improve the resolution of gravity field solutions at regions where terrestrial data are absent (i.e. "fill-in" values of EGM2008), and thus improve altimetry derived WSE for hydrological and hydrodynamic purposes. As concluded by Kingdon et al. (2008) altimetry does provide a higher resolution gravity field than satellite-derived (e.g. GRACE and GOCE) gravity fields and it will be a useful tool to determine a spatially finer equipotential field of large inland lakes. In addition, the forthcoming Surface Water and Ocean Topography (SWOT) mission with wide-swath can make it possible to derive more accurate local geoid undulation.

\section{Summary and conclusions}

The aim of this study was to to retrieve local geoid correction of inland waters over rugged topography. The enhanced geoid leads to a more accurate WSE over lakes, which could be beneficial for hydrologic and hydrodynamic applications.

We used altimetry data from four missions, i.e. CryoSat-2, SARAL, Sentinel-3, and ICESat to derive water levels over Namco. We found that CryoSat-2 overestimates WSE nearshore and SARAL misses measurements close to the lakeshore. CryoSat-2 in SARIn mode does not perform as well as SARAL even though the former has a smaller along-track footprint. The measurements do not represent the lake level even at $5 \mathrm{~km}$ from the lakeshore probably due to the CryoSat-2 processor, onboard tracking system, or combination of both. In contrast, Sentinel-3 is not affected when the measurements are acquired at coast regions. 
We compared the influence of the geoid on altimetry-derived WSE. To investigate the local geoid residual on WSE precision, we retrieved a local geoid signal from CryoSat-2 and SARAL-DF height anomaly. We found that geodetic altimetry data indeed contain geoid information and can be used to improve global geoid models over large lakes. Using high resolution altimetry data sets, i.e., ICESat, SARAL, and Sentinel-3, we validated our improved geoid model. The local geoid correction filed effectively reduced the uncertainty of ICESat, SARAL, and Sentinel-3 retrievals by $9 \%, 37 \%$, and 14\%, respectively. In addition, the accuracy of CryoSat-2 is improved by $8 \%$ and achieves a good agreement with in-situ data in terms of RMSE around $10 \mathrm{~cm}$.

\section{Acknowledgements}

The authors wish to acknowledge ESA, CNES/AVISO, and University of Bristol for providing CryoSat-2, SARAL, Sentinel-3, and ICESat datasets. Special thanks go to the ESA GPOD team who provided us L1b stack data set through the SARvatore platform. The first author is funded by China Scholarship Council, which is greatly acknowledged. The authors would like to thank Marcel Kleinherenbrink and two anonymous reviewers for their constructive comments and suggestions that helped to improve the quality of the manuscript.

Appendix A. Illustration of waveforms of CryoSat-2. Below we show waveform performance of the first 20 measurements, middle open water, and the last 20 measurements close to lakeshore. In the following figures, we only show part of the waveforms to demonstrate the leading edge and retracking position. 


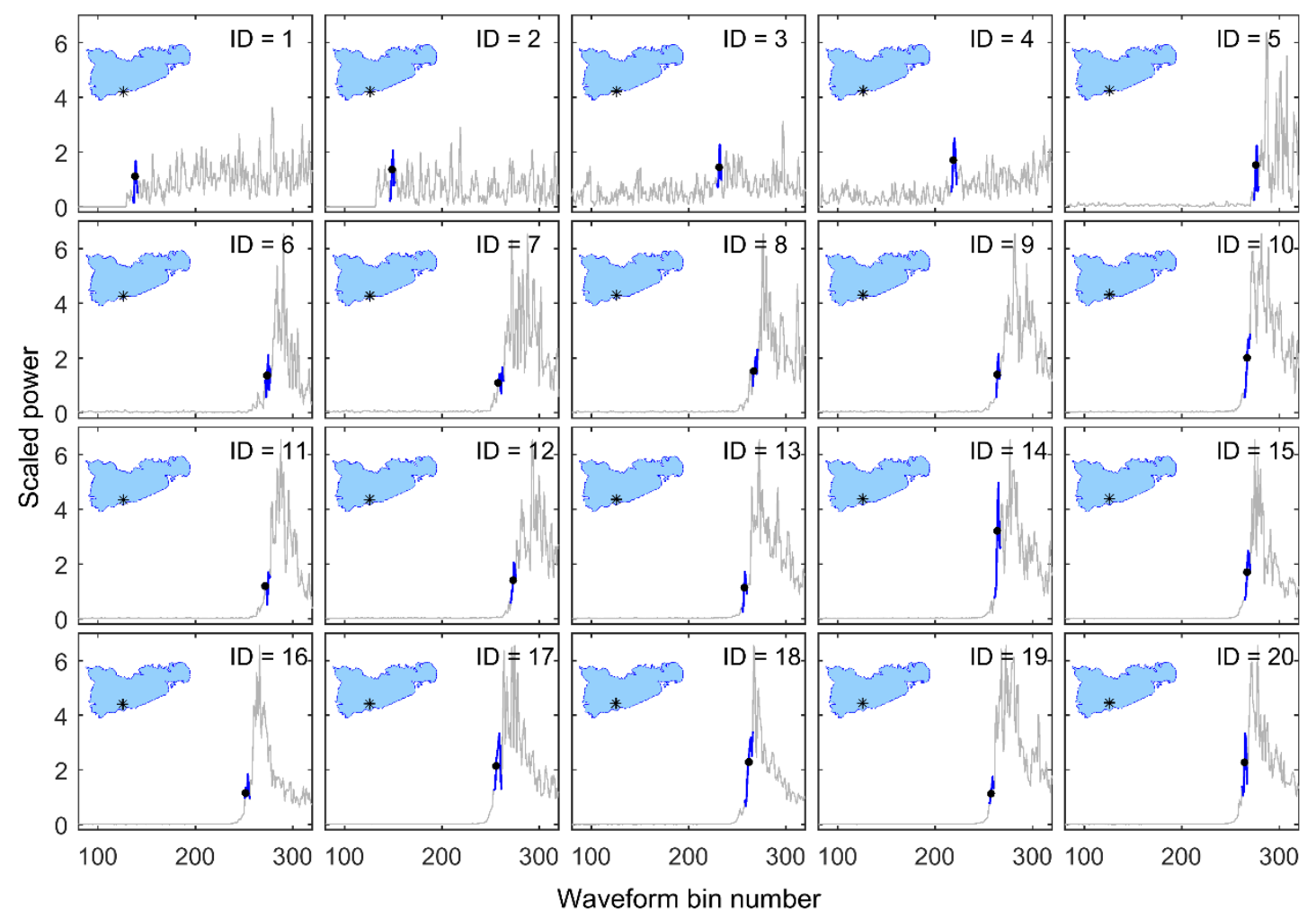

452

453

454

Fig. A1. Waveforms of the first 20 measurements. Corresponding to ascending group 3 shown in Fig. 1. Location of individual waveform is also shown in inset. Grey line indicates the waveform, and blue line shows the retracked leading edge. Black dot indicates the retracked bin. The first 5 messy waveforms are probably due to that the tracking window is not correctly positioned. 


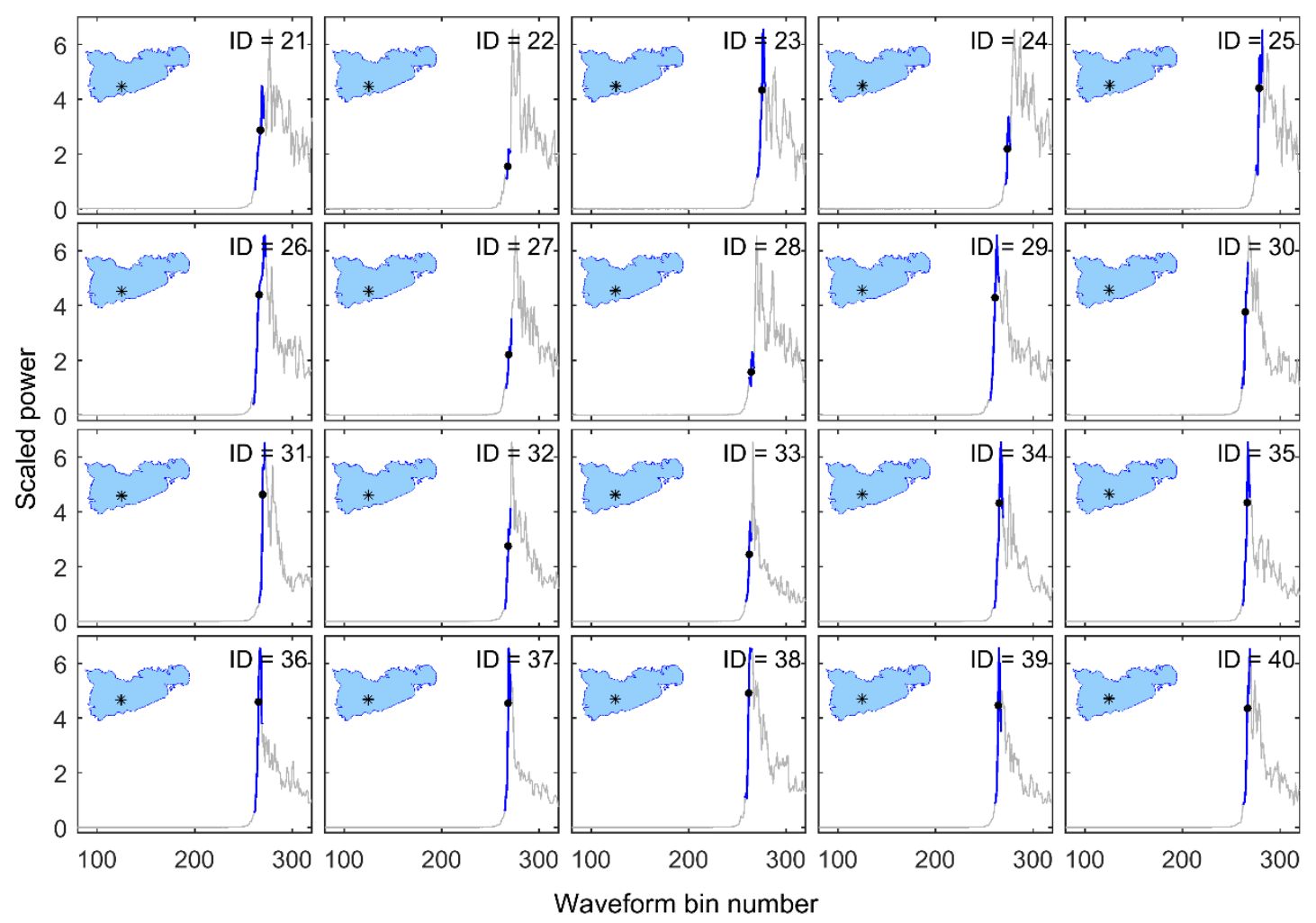

Fig. A2. Similar to Fig. A1, but for open water.

460
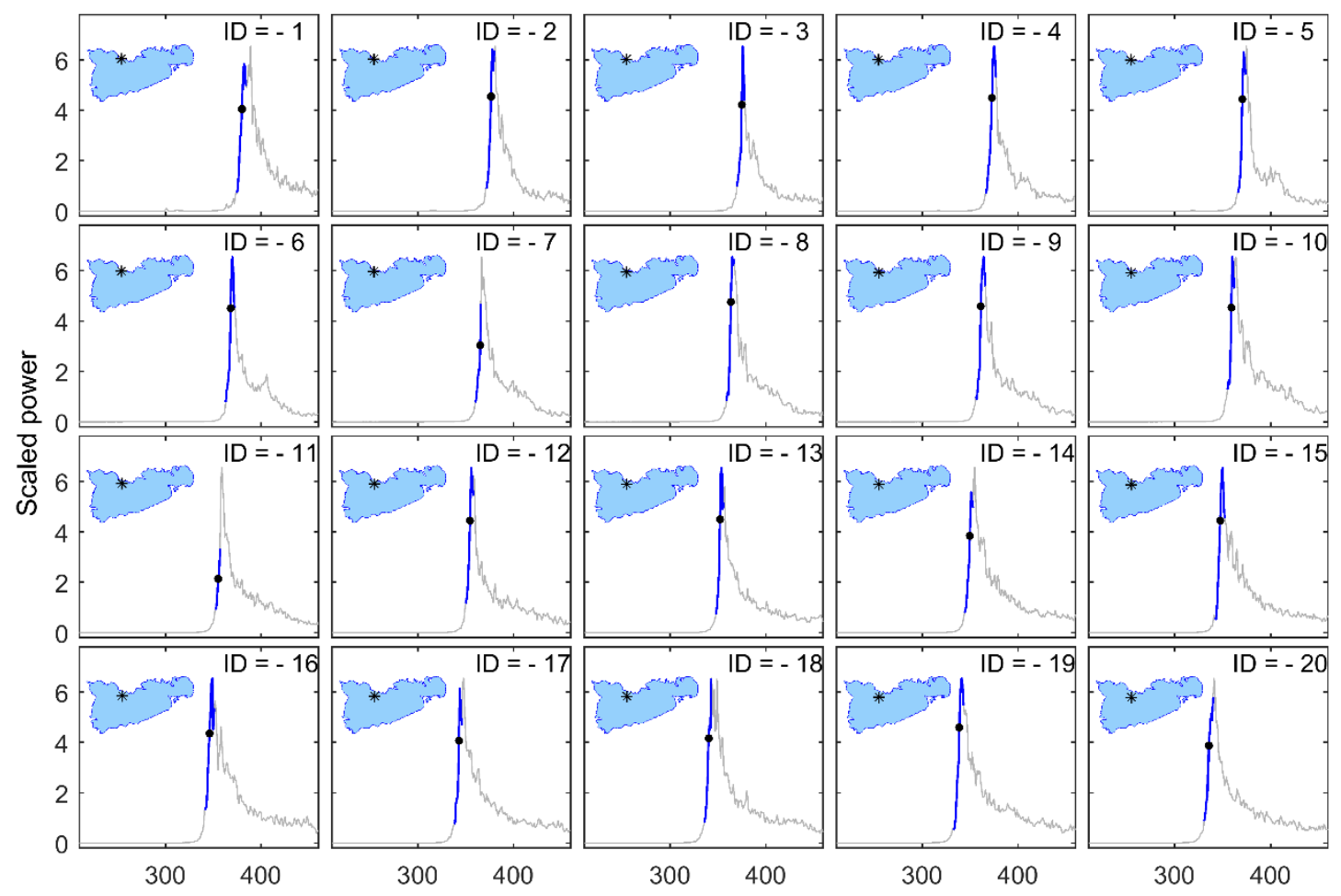

Waveform bin number 
Fig. A3. Similar to Fig. A1, but for last 20 waveforms, indicated by negative numbers. The waveforms are very good even though they are acquired very close to lakeshore.

Appendix B. Illustration of waveforms of Sentinel-3 as a counterpart to CryoSat-2.

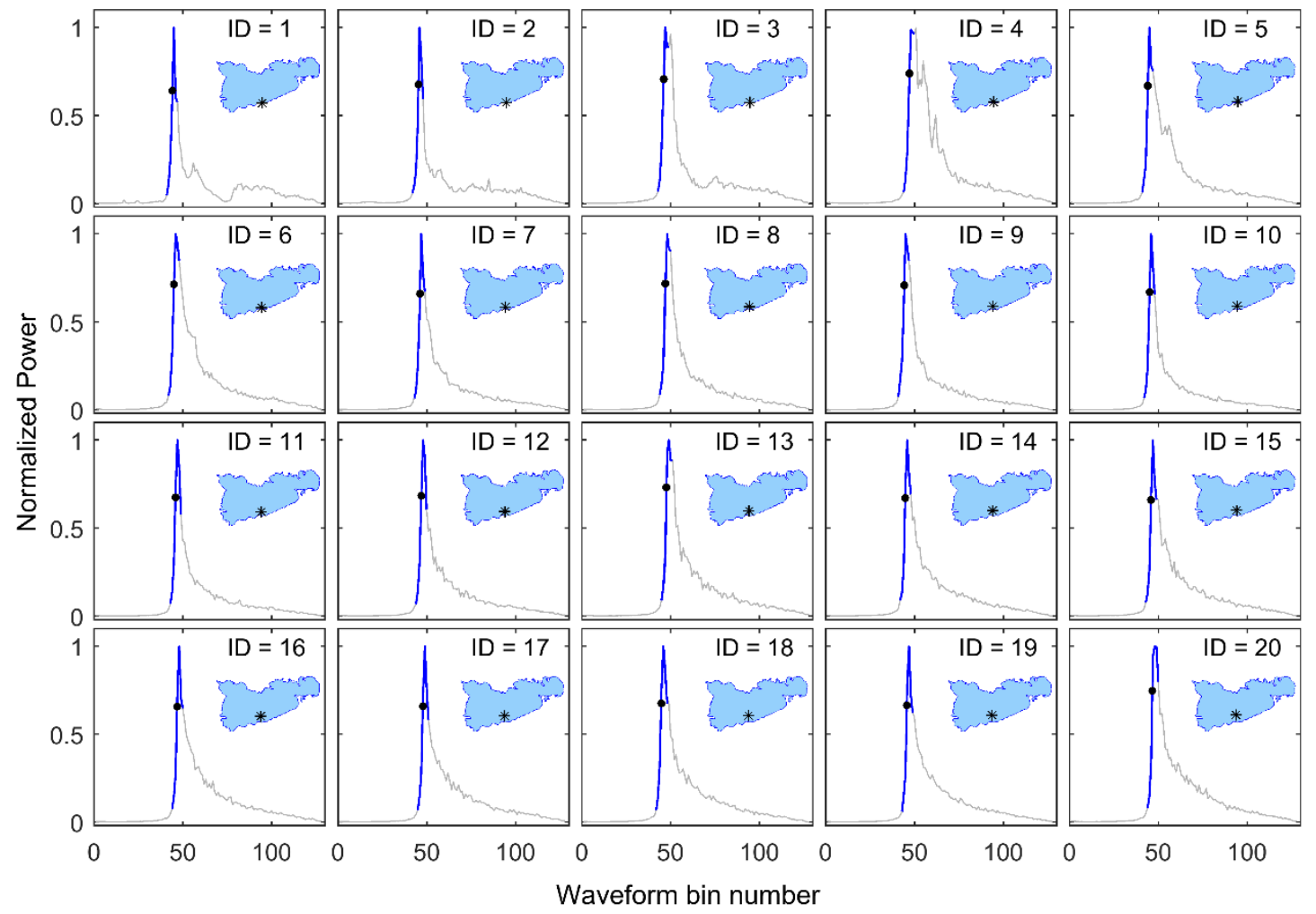

Fig. B1. Waveforms of the first 20 measurements. Corresponding to tracks shown in Fig. 9. Location of individual waveform is also shown in inset. Grey line indicates the whole waveform, and blue line shows the retracked leading edge. Black dot indicates the retracked bin. 


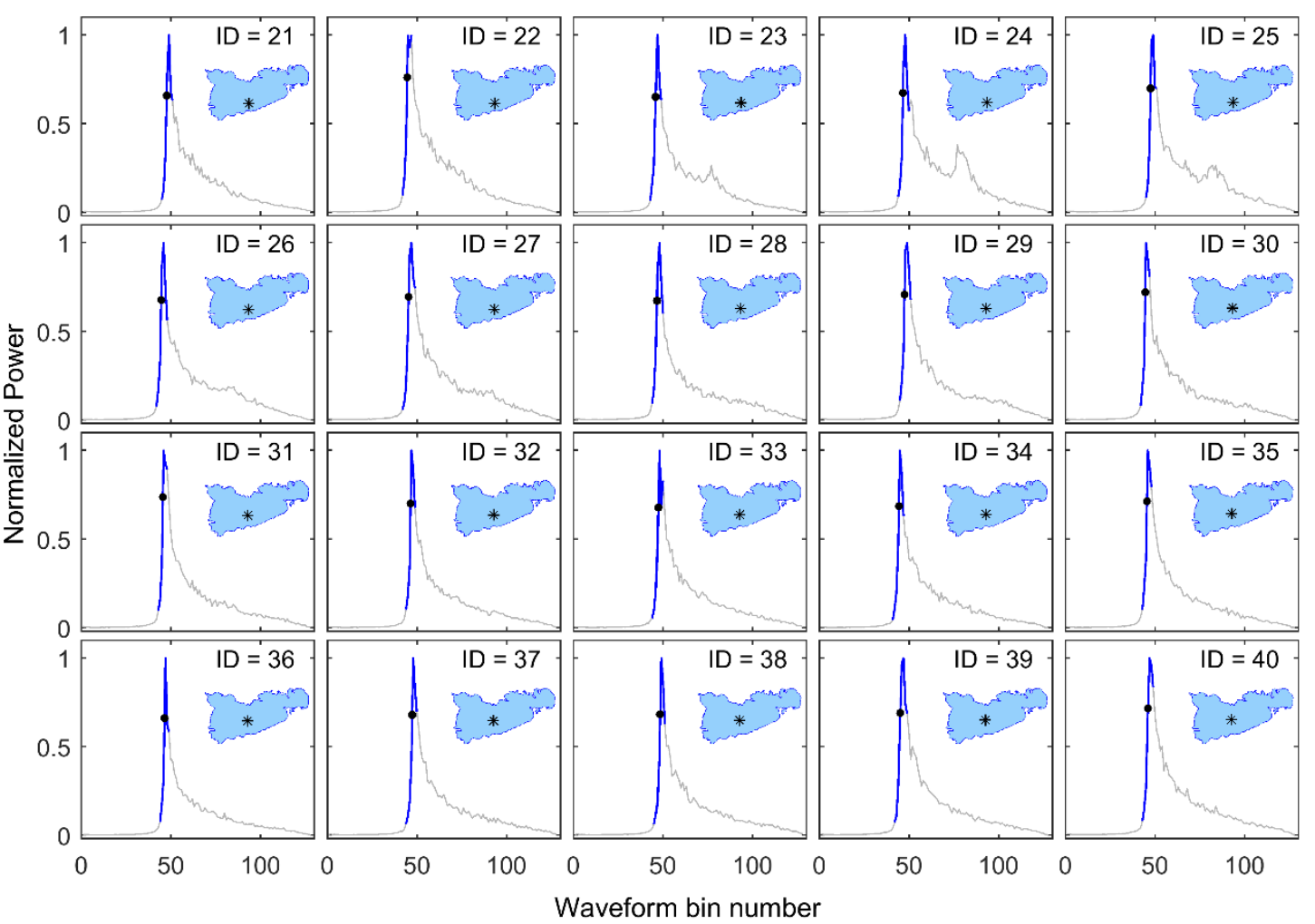

Fig. B2. Similar to B1, but for open water.

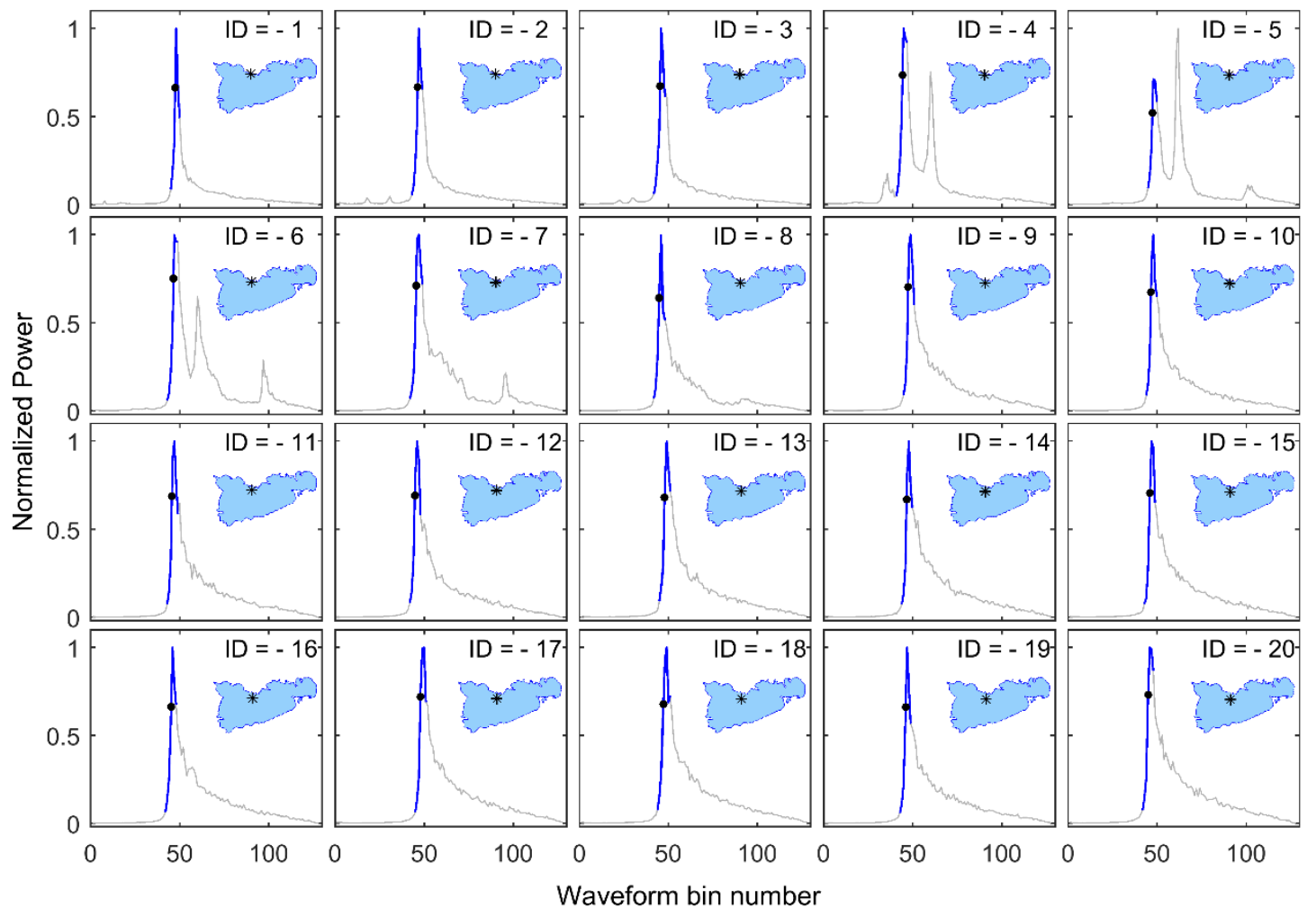

Fig. B3. Similar to B1, but for the last 20 waveforms. 


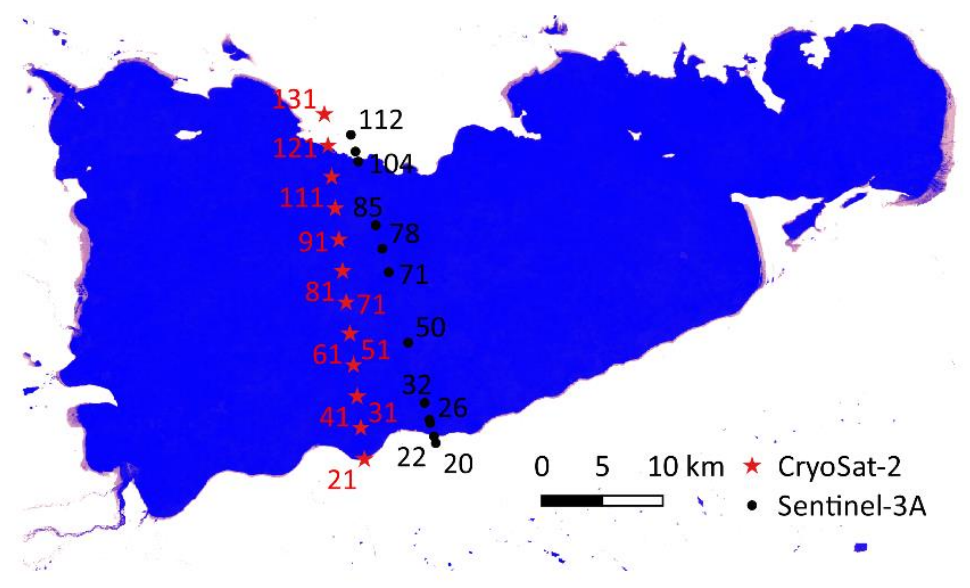

Fig. C1. Locations of measurements from CryoSat-2 and Sentinel-3A

478

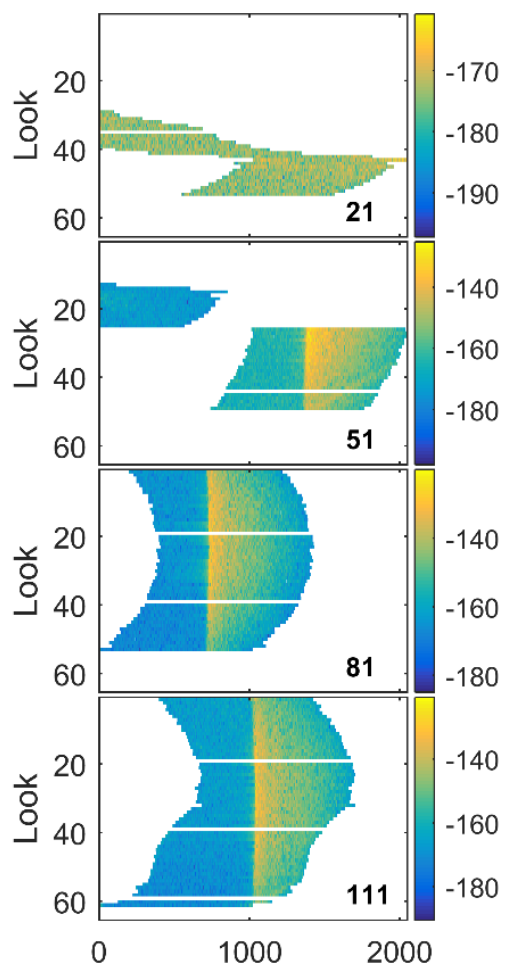

Bin

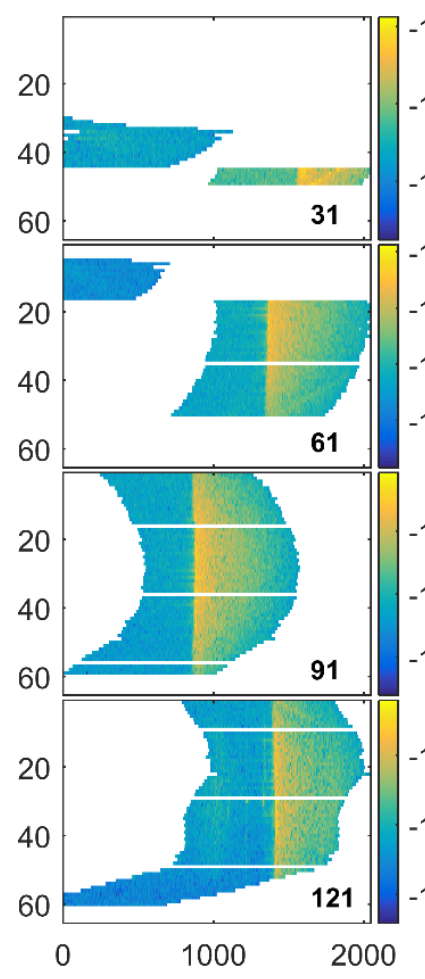

Bin

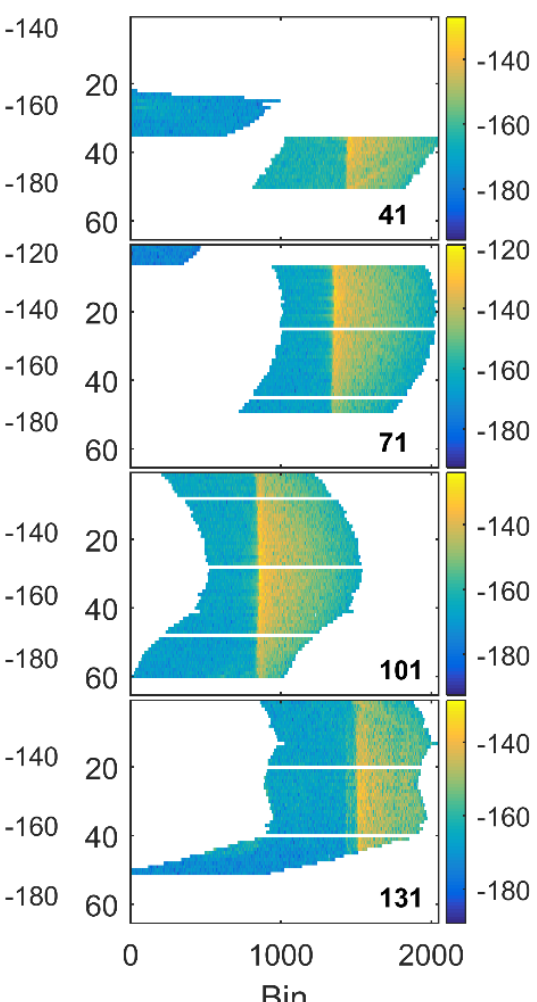

Bin

Fig. C2. Some examples of CryoSat-2 SARIn stack data demonstrating the issue of noisy data along the coast, color scale in $\mathrm{dB}$ and number referring to Fig. $\mathrm{C} 1$. The echoes from the point targets remain with the antenna beam width for about $2 \mathrm{~s}$, i.e. approximately $15 \mathrm{~km}$ in the orbit. The first look is from the extreme forward-looking Dopper beams and the last one from the extreme backward-looking beams. 

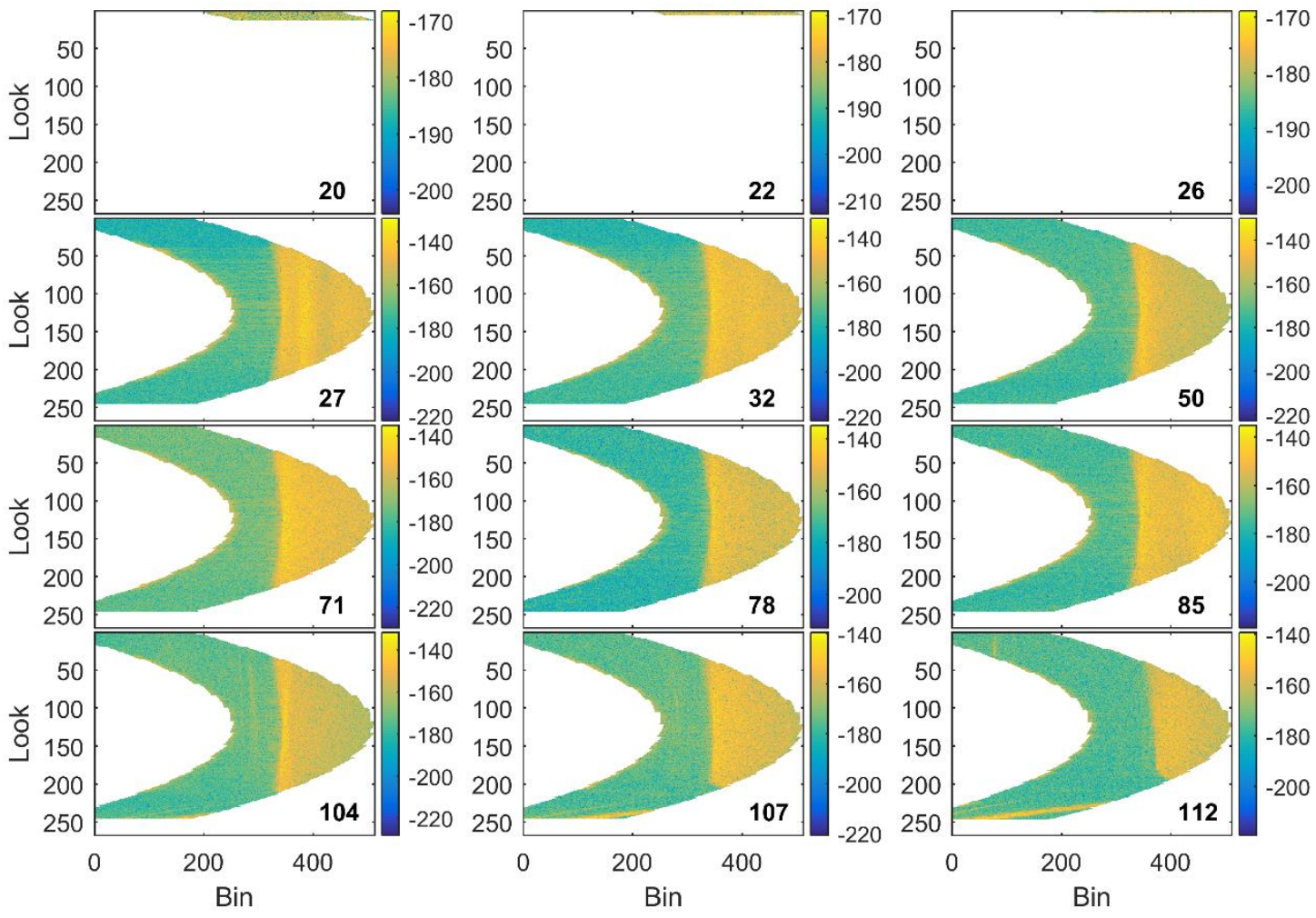

Fig. C3. Illustration of Sentinel-3 SAR stack of Doppler beams (looks) as colored images,

color scale in $\mathrm{dB}$. Some looks are discarded out by means of a noise thresholding or of

Doppler angle thresholding. Number in each sub plot refers to Fig. C1.

\section{References}

Abulaitijiang, A., Andersen, O.B., Stenseng, L., 2015. Coastal sea level from inland CryoSat2 interferometric SAR altimetry. Geophys. Res. Lett. 42, 1841-1847. doi:10.1002/2015GL063131

Akyilmaz, O., Özlüdemir, M.T., Ayan, T., Çelik, R.N., 2009. Soft computing methods for geoidal height transformation. Earth, Planets Sp. 61, 825-833. doi:10.1186/BF03353193

Alsdorf, D.E., Rodriguez, E., Lettenmaier, D.P., 2007. Measuring surface water from space. Rev. Geophys. 45, 1-24. doi:10.1029/2006RG000197.1.INTRODUCTION 
Biancamaria, S., Frappart, F., Leleu, A.-S., Marieu, V., Blumstein, D., Desjonquères, J.-D., Boy, F., Sottolichio, A., Valle-Levinson, A., 2017. Satellite radar altimetry water elevations performance over a 200m wide river: Evaluation over the Garonne River. Adv. Sp. Res. 59, 128-146. doi:10.1016/j.asr.2016.10.008

Blewitt, G., Kreemer, C., Hammond, W.C., Gazeaux, J., 2016. MIDAS robust trend estimator for accurate GPS station velocities without step detection. J. Geophys. Res. Solid Earth 121, 2054-2068. doi:10.1002/2015JB012552

Bonnefond, P., Verron, J., Aublanc, J., Babu, K., Bergé-Nguyen, M., Cancet, M., Chaudhary, A., Crétaux, J.-F., Frappart, F., Haines, B., Laurain, O., Ollivier, A., Poisson, J.-C., Prandi, P., Sharma, R., Thibaut, P., Watson, C., 2018. The Benefits of the Ka-Band as Evidenced from the SARAL/AltiKa Altimetric Mission: Quality Assessment and Unique Characteristics of AltiKa Data. Remote Sens. 10, 83. doi:10.3390/rs10010083

Brenner, A.C., DiMarzio, J.P., Zwally, H.J., 2007. Precision and accuracy of satellite radar and laser altimeter data over the continental ice sheets. IEEE Trans. Geosci. Remote Sens. 45, 321-331. doi:10.1109/TGRS.2006.887172

Chelton, D.B., Ries, J.C., Haines, B.J., Fu, L.-L., Callahan, P.S., 2001. Satellite Altimetry, in: Satellite Altimetry and Earth Sciences: A Handbook of Techniques and Applications. pp. 2504-2510. doi:10.1016/S0074-6142(01)80146-7

CNES, 2016. SARAL / AltiKa Products Handbook.

Crétaux, J.F., Jelinski, W., Calmant, S., Kouraev, A., Vuglinski, V., Bergé-Nguyen, M., 
Gennero, M.C., Nino, F., Abarca Del Rio, R., Cazenave, A., Maisongrande, P., 2011. SOLS: A lake database to monitor in the Near Real Time water level and storage variations from remote sensing data. Adv. Sp. Res. 47, 1497-1507. doi:10.1016/j.asr.2011.01.004

Dehecq, A., Gourmelen, N., Shepherd, A., Cullen, R., Trouvé, E., 2013. Evaluation of CryoSat-2 for height retrieval over the Himalayan range, in: CryoSat-2 Third User Workshop, March 2013. Dresden, Germany.

Dinardo, S., Benveniste, J., 2013. Guidelines for the SAR (Delay-Doppler) L1b Processing.

Dingman, S., 2015. Physical hydrology, Third Edit. ed.

Erol, B., 2011. An automated height transformation using precise geoid models. Sci. Res. Essays 6, 1351-1363. doi:10.5897/SRE10.1119

European Space Agency, Mullar Space Science Laboratory, 2012. CryoSat Product Handbook.

Fecher, T., Pail, R., Gruber, T., Schuh, W.D., Kusche, J., Brockmann, J.M., Loth, I., Müller, S., Eicker, A., Schall, J., Mayer-Gürr, T., Kvas, A., Klinger, B., Rieser, D., Zehentner, N., Baur, O., Höck, E., Krauss, S., Jäggi, A., Meyer, U., Prange, L., Maier, A., 2017. GOCO05c: A New Combined Gravity Field Model Based on Full Normal Equations and Regionally Varying Weighting. Surv. Geophys. 38, 571-590. doi:10.1007/s10712016-9406-y

Forsberg, R., 1985. Gravity field terrain effect computations by FFT. Bull. Géodésique 59, 
342-360. doi:10.1007/BF02521068

Heiskanen, W.A., Moritz, H., 1967. Physical geodesy. W. H. Freeman \& Co Ltd, San Francisco and London.

Hirt, C., 2011. Assessment of EGM2008 over Germany using accurate quasigeoid heights from vertical deflections, GCG05 and GPS/levelling. ZFV - Zeitschrift fur Geodasie, Geoinf. und Landmanagement 136, 138-149.

Hirt, C., Featherstone, W.E., Marti, U., 2010. Combining EGM2008 and SRTM/DTM2006.0 residual terrain model data to improve quasigeoid computations in mountainous areas devoid of gravity data. J. Geod. 84, 557-567. doi:10.1007/s00190-010-0395-1

Hwang, C., Cheng, Y.-S., Han, J., Kao, R., Huang, C.-Y., Wei, S.-H., Wang, H., 2016. MultiDecadal Monitoring of Lake Level Changes in the Qinghai-Tibet Plateau by the TOPEX/Poseidon-Family Altimeters: Climate Implication. Remote Sens. 8, 446. doi:10.3390/rs8060446

Jain, M., Andersen, O.B., Dall, J., Stenseng, L., 2015. Sea surface height determination in the Arctic using Cryosat-2 SAR data from primary peak empirical retrackers. Adv. Sp. Res. 55, 40-50. doi:10.1016/j.asr.2014.09.006

Jiang, L., Nielsen, K., Andersen, O.B., Bauer-Gottwein, P., 2017a. Monitoring recent lake level variations on the Tibetan Plateau using CryoSat-2 SARIn mode data. J. Hydrol. 544, 109-124. doi:10.1016/j.jhydrol.2016.11.024

Jiang, L., Nielsen, K., Andersen, O.B., Bauer-Gottwein, P., 2017b. CryoSat-2 radar altimetry 

for monitoring China's freshwater resources. Remote Sens. Environ. 200, 125-139. doi:10.1016/j.rse.2017.08.015

Jiang, L., Schneider, R., Andersen, O.B., Bauer-Gottwein, P., 2017c. CryoSat-2 Altimetry Applications over Rivers and Lakes. Water 9, 211. doi:10.3390/w9030211

Ke, C.-Q., Tao, A.-Q., Jin, X., 2013. Variability in the ice phenology of Nam Co Lake in central Tibet from scanning multichannel microwave radiometer and special sensor microwave/imager: 1978 to 2013. J. Appl. Remote Sens. 7, 073477. doi:10.1117/1.JRS.7.073477

Kingdon, R., Hwang, C., Hsiao, Y.S., Santos, M., 2008. Gravity anomalies from retracked ERS and geosat altimetry over the Great Lakes: Accuracy assessment and problems. Terr. Atmos. Ocean. Sci. 19, 93-101. doi:10.3319/TAO.2008.19.1-2.93(SA)

Kleinherenbrink, M., Ditmar, P.G., Lindenbergh, R.C., 2014. Retracking Cryosat data in the SARIn mode and robust lake level extraction. Remote Sens. Environ. 152, 38-50. doi:10.1016/j.rse.2014.05.014

Kropáček, J., Maussion, F., Chen, F., Hoerz, S., Hochschild, V., 2013. Analysis of ice phenology of lakes on the Tibetan Plateau from MODIS data. Cryosph. 7, 287-301. doi:10.5194/tc-7-287-2013

Lei, Y., Yao, T., Bird, B.W., Yang, K., Zhai, J., Sheng, Y., 2013. Coherent lake growth on the central Tibetan Plateau since the 1970s: Characterization and attribution. J. Hydrol. 483, 61-67. doi:10.1016/j.jhydrol.2013.01.003 
Leys, C., Ley, C., Klein, O., Bernard, P., Licata, L., 2013. Detecting outliers: Do not use standard deviation around the mean, use absolute deviation around the median. J. Exp. Soc. Psychol. 49, 764-766. doi:10.1016/j.jesp.2013.03.013

Li, J., Shen, W., Zhou, X., 2015. Direct regional quasi-geoid determination using EGM2008 and DEM: A case study for Mainland China and its vicinity areas. Geod. Geodyn. 6, 437-443. doi:10.1016/j.geog.2015.12.002

Mazloff, M.R., Gille, S.T., Cornuelle, B., 2014. Improving the geoid: Combining altimetry and mean dynamic topography in the California coastal ocean. Geophys. Res. Lett. 41, 8944-8952. doi:10.1002/2014GL062402

Meyer, T.H., Roman, D.R., Zilkoski, D.B., Meyer, T.H., Roman, D.R., David, B., 2006. What Does Height Really Mean? Part III: Height Systems. Surv. L. Inf. Sci. 66, 149-160.

National Geodetic Survey, 1986. Geodetic glossary. U.S. Dept. of Commerce, National Oceanic and Atmospheric Administration, National Ocean Service, Charting and Geodetic Services, 1986.

Nielsen, K., Stenseng, L., Andersen, O.B., Knudsen, P., 2017. The Performance and Potentials of the CryoSat-2 SAR and SARIn Modes for Lake Level Estimation. Water 9, 374. doi:10.3390/w9060374

Nielsen, K., Stenseng, L., Andersen, O.B., Villadsen, H., Knudsen, P., 2015. Validation of CryoSat-2 SAR mode based lake levels. Remote Sens. Environ. 171, 162-170. doi:10.1016/j.rse.2015.10.023 
Pavlis, N.K., Holmes, S.A., Kenyon, S.C., Factor, J.K., 2012. The development and evaluation of the Earth Gravitational Model 2008 (EGM2008). J. Geophys. Res. Solid Earth 117, n/a-n/a. doi:10.1029/2011JB008916

Schneider, R., Godiksen, P.N., Villadsen, H., Madsen, H., Bauer-Gottwein, P., 2017. Application of CryoSat-2 altimetry data for river analysis and modelling. Hydrol. Earth Syst. Sci. 21, 751-764. doi:10.5194/hess-21-751-2017

Schneider, R., Ridler, M.E., Godiksen, P.N., Madsen, H., Bauer-Gottwein, P., 2018a. A data assimilation system combining CryoSat-2 data and hydrodynamic river models. J. Hydrol. 557, 197-210. doi:10.1016/j.jhydrol.2017.11.052

Schneider, R., Tarpanelli, A., Nielsen, K., Madsen, H., Bauer-Gottwein, P., 2018b. Evaluation of multi-mode CryoSat-2 altimetry data over the Po River against in situ data and a hydrodynamic model. Adv. Water Resour. 112, 17-26. doi:10.1016/j.advwatres.2017.11.027

Schwatke, C., Dettmering, D., Bosch, W., Seitz, F., 2015. DAHITI - An innovative approach for estimating water level time series over inland waters using multi-mission satellite altimetry. Hydrol. Earth Syst. Sci. 19, 4345-4364. doi:10.5194/hess-19-4345-2015

Seo, D., Sigdel, R., Kwon, K.H., Lee, Y.S., 2010. 3-D hydrodynamic modeling of Yongdam Lake, Korea using EFDC. Desalin. Water Treat. 19, 42-48. doi:10.5004/dwt.2010.1894

She, Y., Fu, G., Wang, Z., Liu, T., Xu, C., Jin, H., 2016. Gravity anomalies and lithospheric flexure around the Longmen Shan deduced from combinations of in situ observations 
617

Song, C., Huang, B., Ke, L., Richards, K.S., 2014. Seasonal and abrupt changes in the water level of closed lakes on the Tibetan Plateau and implications for climate impacts. J. Hydrol. 514, 131-144. doi:10.1016/j.jhydrol.2014.04.018

Steunou, N., Desjonqu??res, J.D., Picot, N., Sengenes, P., Noubel, J., Poisson, J.C., 2015. AltiKa Altimeter: Instrument Description and In Flight Performance. Mar. Geod. 38, 22-42. doi:10.1080/01490419.2014.988835

Tseng, K.H., Chang, C.P., Shum, C.K., Kuo, C.Y., Liu, K.T., Shang, K., Jia, Y., Sun, J., 2016. Quantifying freshwater mass balance in the central Tibetan Plateau by integrating satellite remote sensing, altimetry, and gravimetry. Remote Sens. 8. doi:10.3390/rs8060441

Villadsen, H., Deng, X., Andersen, O.B., Stenseng, L., Nielsen, K., Knudsen, P., 2016. Improved inland water levels from SAR altimetry using novel empirical and physical retrackers. J. Hydrol. 537, 234-247. doi:10.1016/j.jhydrol.2016.03.051

Wang, J., Zhu, L., Daut, G., Ju, J., Lin, X., Wang, Y., Zhen, X., 2009. Investigation of bathymetry and water quality of Lake Nam Co, the largest lake on the central Tibetan Plateau, China. Limnology 10, 149-158. doi:10.1007/s10201-009-0266-8

Wingham, D.J., Francis, C.R., Baker, S., Bouzinac, C., Brockley, D., Cullen, R., de ChateauThierry, P., Laxon, S.W., Mallow, U., Mavrocordatos, C., Phalippou, L., Ratier, G., Rey, L., Rostan, F., Viau, P., Wallis, D.W., 2006. CryoSat: A mission to determine the 
fluctuations in Earth's land and marine ice fields. Adv. Sp. Res. 37, 841-871. doi:10.1016/j.asr.2005.07.027

Xue, P., Pal, J.S., Ye, X., Lenters, J.D., Huang, C., Chu, P.Y., 2017. Improving the Simulation of Large Lakes in Regional Climate Modeling: Two-Way Lake-Atmosphere Coupling with a 3D Hydrodynamic Model of the Great Lakes. J. Clim. 30, 1605-1627. doi:10.1175/JCLI-D-16-0225.1

Yilmaz, N., 2008. Comparison of different height systems. Geo-spatial Inf. Sci. 11, 209-214. doi:10.1007/s11806-008-0074-z

Zandagba, J., Moussa, M., Obada, E., Afouda, A., 2016. Hydrodynamic Modeling of Nokoué Lake in Benin. Hydrology 3, 44. doi:10.3390/hydrology3040044

Zhang, G., Xie, H., Kang, S., Yi, D., Ackley, S.F., 2011. Monitoring lake level changes on the Tibetan Plateau using ICESat altimetry data (2003-2009). Remote Sens. Environ. 115, 1733-1742. doi:10.1016/j.rse.2011.03.005

Zlinszky, A., Timár, G., Weber, R., Székely, B., Briese, C., Ressl, C., Pfeifer, N., 2014. Observation of a local gravity potential isosurface by airborne lidar of lake Balaton, Hungary. Solid Earth 5, 355-369. doi:10.5194/se-5-355-2014

Zwally, H.J., Schutz, B., Abdalati, W., Abshire, J., Bentley, C., Brenner, A., Bufton, J., Dezio, J., Hancock, D., Harding, D., Herring, T., Minster, B., Quinn, K., Palm, S., Spinhirne, J., Thomas, R., 2002. ICESat's laser measurements of polar ice, atmosphere, ocean, and land. J. Geodyn. 34, 405-445. doi:10.1016/S0264-3707(02)00042-X 
Zwally, H.J., Yi, D., Kwok, R., Zhao, Y., 2008. ICESat measurements of sea ice freeboard and estimates of sea ice thickness in the Weddell Sea. J. Geophys. Res. 113, C02S15. doi:10.1029/2007JC004284 59 